\title{
European Association of Urology Guidelines on Sexual and Reproductive Health-2021 Update: Male Sexual Dysfunction
}

\author{
Andrea Salonia ${ }^{a, b, *}$, Carlo Bettocchi ${ }^{c}$, Luca Boeri ${ }^{d}$, Paolo Capogrosso ${ }^{e}$, Joana Carvalho ${ }^{f}$, \\ Nusret Can Cilesiz ${ }^{g}$, Andrea Cocci ${ }^{h}$, Giovanni Corona ${ }^{i}$, Kostantinos Dimitropoulos ${ }^{j, k}$, \\ Murat Gül $^{l}$, Georgios Hatzichristodoulou ${ }^{m}$, T. Hugh Jones ${ }^{n}$, Ates Kadioglu ${ }^{o}$, \\ Juan Ignatio Martínez Salamanca ${ }^{p}$, Uros Milenkovic ${ }^{q}$, Vaibhav Modgil ${ }^{r}$, Giorgio Ivan Russo ${ }^{s}$, \\ Ege Can Serefoglu ${ }^{t}$, Tharu Tharakan ${ }^{u, v}$, Paolo Verze ${ }^{w}$, Suks Minhas ${ }^{u}$, \\ on behalf of the EAU Working Group on Male Sexual and Reproductive Health
}

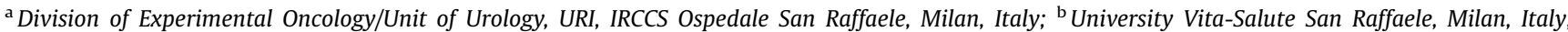
${ }^{\mathrm{c}}$ Department of Urology, University of Foggia, Foggia, Italy; ${ }^{\mathrm{d}}$ Department of Urology, Foundation IRCCS Ca' Granda - Ospedale Maggiore Policlinico, University of Milan, Milan, Italy; ${ }^{\mathrm{e}}$ Department of Urology and Andrology, Ospedale di Circolo and Macchi Foundation, Varese, Italy; ${ }^{\mathrm{f}}$ CPUP: Center for Psychology of Porto University, Faculty of Psychology and Educational Sciences, Porto University, Porto, Portugal; ${ }^{g}$ Department of Urology, Taksim Training E Research Hospital, Istanbul, Turkey; ${ }^{\mathrm{h}}$ Department of Minimally Invasive and Robotic Urologic Surgery and Kidney Transplantation, University of Florence, Florence, Italy; ${ }^{\mathrm{i}}$ Endocrinology Unit, Medical Department, Maggiore-Bellaria Hospital, Bologna, Italy; ${ }^{\mathrm{j}}$ Academic Urology Unit, Institute of Applied Health Sciences, University of Aberdeen, Aberdeen, UK; ${ }^{k}$ Department of Urology, Aberdeen Royal Infirmary, NHS Grampian, Aberdeen, UK; ${ }^{1}$ School of Medicine, Department of Urology, Selcuk University, Konya, Turkey; ${ }^{\mathrm{m}}$ Department of Urology, Martha-Maria Hospital Nuremberg, Nuremberg, Germany; ${ }^{\mathrm{n}}$ Centre for Diabetes and Endocrinology, Barnsley Hospital NHS Trust, Barnsley, UK; ${ }^{\circ}$ Department of Urology, Istanbul University Istanbul School of Medicine, Istanbul, Turkey; ${ }^{\mathrm{p}}$ Department of Urology, Hospital Universitario Puerta de Hierro-Majadahonda, Lyx Institute of Urology, Universidad Francisco de Vitoria, Madrid, Spain; ${ }^{\mathrm{q}}$ Department of Urology, University Hospitals Leuven, Leuven, Belgium; ${ }^{\mathrm{r}}$ Manchester Andrology Centre, Manchester Royal Infirmary, Manchester University Hospitals NHS Foundation Trust, Manchester, UK; ${ }^{\mathrm{s}}$ Urology Section, Department of Surgery, University of Catania, Catania, Italy; ${ }^{\mathrm{t}}$ Department of Urology, Biruni University School of Medicine, Istanbul, Turkey; " Department of Urology, Imperial Healthcare NHS Trust, Charing Cross Hospital, London, UK; ${ }^{\mathrm{v}}$ Section of Investigative Medicine, Department of Medicine, Imperial College London, London, UK; ${ }^{\mathrm{w}}$ Department of Medicine and Surgery "Scuola Medica Salernitana", University of Salerno, Fisciano, Campania, Italy

https://doi.org/10.1016/j.eururo.2021.06.007

0302-2838/@ 2021 European Association of Urology. Published by Elsevier B.V. All rights reserved.

* Corresponding author. Division of Experimental Oncology/Unit of Urology, URI-Urological Research Institute, IRCCS Ospedale San Raffaele, Via Olgettina 60, 20132 Milan, Italy. Tel. +39 0226435506. E-mail address: salonia.andrea@hsr.it (A. Salonia). 


\section{Article info}

\section{Article history:}

Accepted June 9, 2021

\section{Associate Editor: James Catto}

\section{Keywords: \\ Guidelines \\ Male \\ Testosterone \\ Hypogonadism \\ Sexual dysfunction \\ Erectile dysfunction \\ Ejaculatory disorders \\ Premature ejaculation \\ Haemospermia}

\section{EU *ACME}

www.eu-acme.org/europeanurology

Please visit www.eu-acme.org/ europeanurology to answer questions online. The EU-ACME credits will then be attributed automatically.

\begin{abstract}
Context: The present summary of the European Association of Urology (EAU) guidelines is based on the latest guidelines on male sexual health published in March 2021, with a last comprehensive update in January 2021.

Objective: To present a summary of the 2021 version of the EAU guidelines on sexual and reproductive health.

Evidence acquisition: A literature review was performed up to January 2021. The guidelines were updated, and a strength rating for each recommendation was included based on either a systematic review of the evidence or a consensus opinion from the expert panel. Evidence synthesis: Late-onset hypogonadism is a clinical condition in the ageing male combining low levels of circulating testosterone and specific symptoms associated with impaired hormone production and/or action. A comprehensive diagnostic and therapeutic work-up, along with screening recommendations and contraindications, is provided. Erectile dysfunction (ED) is the persistent inability to attain and maintain an erection sufficient to permit satisfactory sexual performance. Along with a detailed basic and advanced diagnostic approach, a novel decision-making algorithm for treating $\mathrm{ED}$ in order to better tailor therapy to individual patients is provided. The EAU guidelines have adopted the definition of premature ejaculation (PE), which has been developed by the International Society for Sexual Medicine. After the subtype of PE has been defined, patient's expectations should be discussed thoroughly and pharmacotherapy must be considered as the first-line treatment for patients with lifelong PE, whereas treating the underlying cause must be the initial goal for patients with acquired PE. Haemospermia is defined as the appearance of blood in the ejaculate. Several reasons of haemospermia have been acknowledged; the primary goal over the management work-up is to exclude malignant conditions and treat any other underlying cause.

Conclusions: The 2021 guidelines on sexual and reproductive health summarise the most recent findings, and advise in terms of diagnosis and treatment of male hypogonadism and sexual dysfunction for their use in clinical practice. These guidelines reflect the multidisciplinary nature of their management.

Patient summary: Updated European Association of Urology guidelines on sexual and reproductive health are presented, addressing the diagnosis and treatment of the most prevalent conditions in men. Patients must be fully informed of all relevant diagnostic and therapeutic options and, together with their treating physicians, decide on optimal personalised management strategies.
\end{abstract}

(C) 2021 European Association of Urology. Published by Elsevier B.V. All rights reserved.

\section{Introduction}

The most recent summary of the European Association of Urology (EAU) guidelines on male sexual health were published in 2010 [1] and 2012 [2]. The present summary is based on the latest guidelines published in March 2021 [3], with the last comprehensive update in January 2021. The 2021 version of the EAU guideline document is a further comprehensive update of the 2020 guidelines, which already includes an update of the 2018 versions of male sexual dysfunction, Male infertility, and male hypogonadism, along with several new topics. It must be emphasised that guidelines present the best evidence available to the experts, who have participated fully in the evaluation of all the material revised systematically for individual chapters.

This article summarises the EAU guideline recommendations on male sexual health management (namely, lateonset hypogonadism [LOH], erectile dysfunction [ED], premature ejaculation $[\mathrm{PE}]$, and recurrent haemospermia). The panel presents a summary of these latter conditions because of their epidemiological importance, and a number of innovative updates in terms of their management and their relevance to men's health. Moreover, the full text on male sexual health management can be found in the EAU guideline textbook and at uroweb.org [3].

\section{Evidence acquisition}

The panel performed a broad and comprehensive literature search, covering all sections of the guidelines. Databases searched included Medline, EMBASE, and the Cochrane Libraries, covering a time frame between 2013 and 2020 and restricted to English-language publications.

A strength rating has been provided for each recommendation according to the EAU Guideline Office methodology (modified from the Grading of Recommendations Assessment, Development and Evaluation [GRADE] methodology) [4].

\section{Evidence synthesis}

\subsection{Male hypogonadism}

\subsubsection{Definition and epidemiology}

Male hypogonadism is a disorder associated with decreased functional activity of the testes, with decreased production and/or action of androgens and/or impaired sperm production [5]. This is caused by poor testicular function or as a result of inadequate stimulation of the testes by the hypothalamic-pituitary-gonadal (HPG) axis. Likewise, several congenital or acquired disorders causing impaired action of androgens have also been described [5]. 
LOH is a clinical condition in the ageing male, which, by definition, must comprise specific symptoms and biochemical evidence of testosterone deficiency $[5,6]$. It is a condition diagnosed in the absence of an identifiable classical cause of hypogonadism, which becomes more prevalent with age, occurring usually, but not exclusively, in men over $40 \mathrm{yr}$ of age. The present guideline summary will specifically address the management of $\mathrm{LOH}$.

In men aged between 40 and $79 \mathrm{yr}$, the incidence of symptomatic hypogonadism varies between $2.1 \%$ and $5.7 \%$ $[7,8]$. The incidence of hypogonadism has been reported to be 12.3 and 11.7 cases per 1000 people per year [9]. Testosterone production declines as a function of age, and the prevalence of hypogonadism increases with ageing; moreover, there is a higher prevalence of hypogonadism within specific populations, including men with type 2 diabetes (T2DM), metabolic syndrome (MetS), obesity, cardiovascular disease (CVD), chronic obstructive pulmonary disease (COPD), renal disease, and cancer [9-12]. Klinefelter syndrome, a trisomy associated with a 47,XXY karyotype, is the most prevalent genetic cause of primary hypogonadism, with a global prevalence of $1 / 500-$ 1000 live male births [13].

\subsubsection{Classification and causes of male hypogonadism}

Male hypogonadism can be classified according to the origin of the underlying aetiology into primary, if a consequence of testicular dysfunction, and secondary, if due to a pituitary or hypothalamic dysfunction (Supplementary Table 1). Primary hypogonadism is also called hypergonadotropic hypogonadism, since the pituitary tries compensating the dysfunctional testis by increasing central stimulation. Conversely, in secondary hypogonadism (also called hypogonadotropic hypogonadism), the testis is inadequately stimulated by gonadotropins, usually with inappropriately normal or reduced gonadotropin levels [6,14]. A compensated or subclinical form of hypogonadism, characterised by normal testosterone serum levels and elevated luteinising hormone (LH) production, has also been reported [15]; the clinical significance of the latter condition is unclear [16]. Finally, hypogonadism can also result from a group of several conditions leading to reduced sensitivity/insensitivity to testosterone and its metabolites (Supplementary Table 1) [5,14]. This classification, based on the aetiology of hypogonadism, allows the clinician to select appropriate treatment adequately. Organic hypogonadism is characterised by any proven pathology affecting the HPG axis and should be treated with conventional medications (ie, gonadotropins or testosterone therapy). Conversely, functional hypogonadism is based on the absence of any recognised organic alterations in the HPG axis and should be treated first by resolving or improving the associated comorbidities; therefore, the need for testosterone therapy has been questioned $[17,18]$.

\subsubsection{Diagnostic evaluation of male hypogonadism}

Potential aetiology and risk factors associated with male hypogonadism are shown in Supplementary Table 1 . The phenotype of the hypogonadal patient appears to be independent of the aetiology underlying the problem but is more often affected by the age of onset of hypogonadism. When hypogonadism occurs in adulthood, especially in the case of functional hypogonadism, symptoms can often be relatively mild, difficult to recognise, and frequently confused with the ageing process $[5,14]$ or with comorbid chronic conditions. Several nonspecific clinical features (eg, fatigue, weakness, and decreased energy) as well as sexual impairment may be clinical manifestations. The European Male Ageing Study (EMAS) showed that a triad of sexual symptoms, including low libido, reduced spontaneous erections, and ED, are typically associated with a decrease in serum testosterone levels [7]. Conversely, psychological and physical symptoms were less informative (Supplementary Table 2) [7]. As detailed, the mainstay of an LOH diagnosis includes the presence of signs and symptoms consistent with hypogonadism, coupled with biochemical evidence of low morning serum total testosterone levels on two or more occasions, measured with a reliable assay. Testosterone levels show a circadian variation, which persists in ageing men [19]. Likewise, testosterone levels are potentially influenced by food intake $[5,20]$; hence, serum total testosterone should be measured in fasting conditions and in the morning (between 7.00 and 11.00 hours). Moreover, a confirmatory measurement should always be undertaken in the case of a primary pathological value and certainly before starting any testosterone therapy. Liquid chromatography-tandem mass

Table 1 - Recommendations for screening and diagnostic evaluation of late-onset hypogonadism

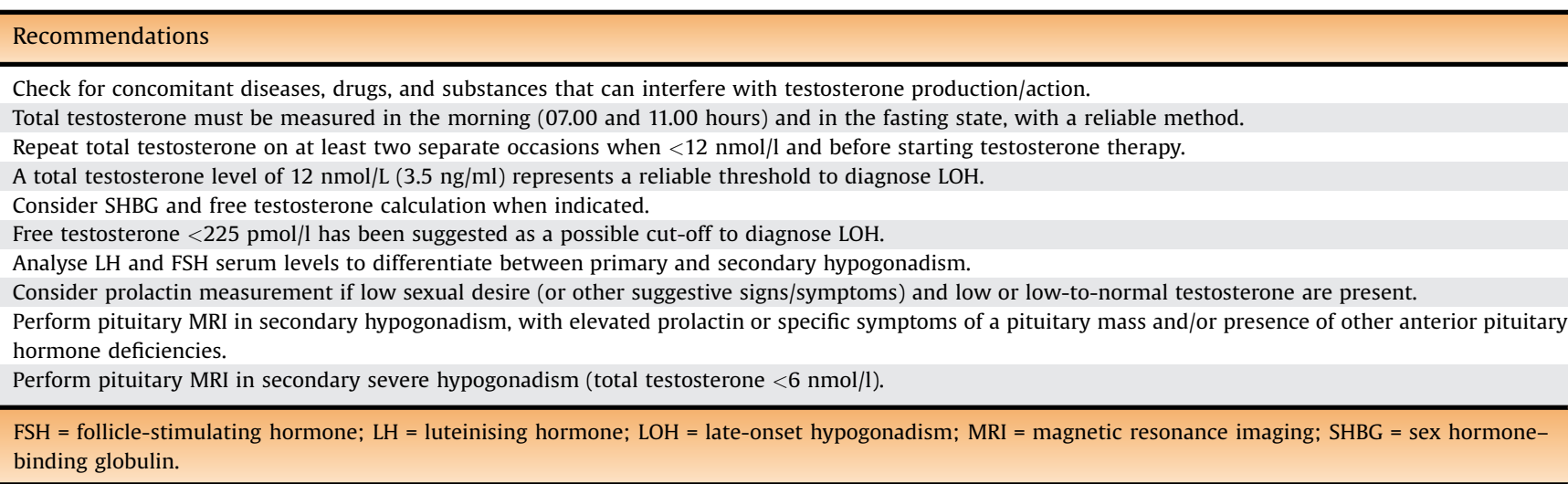




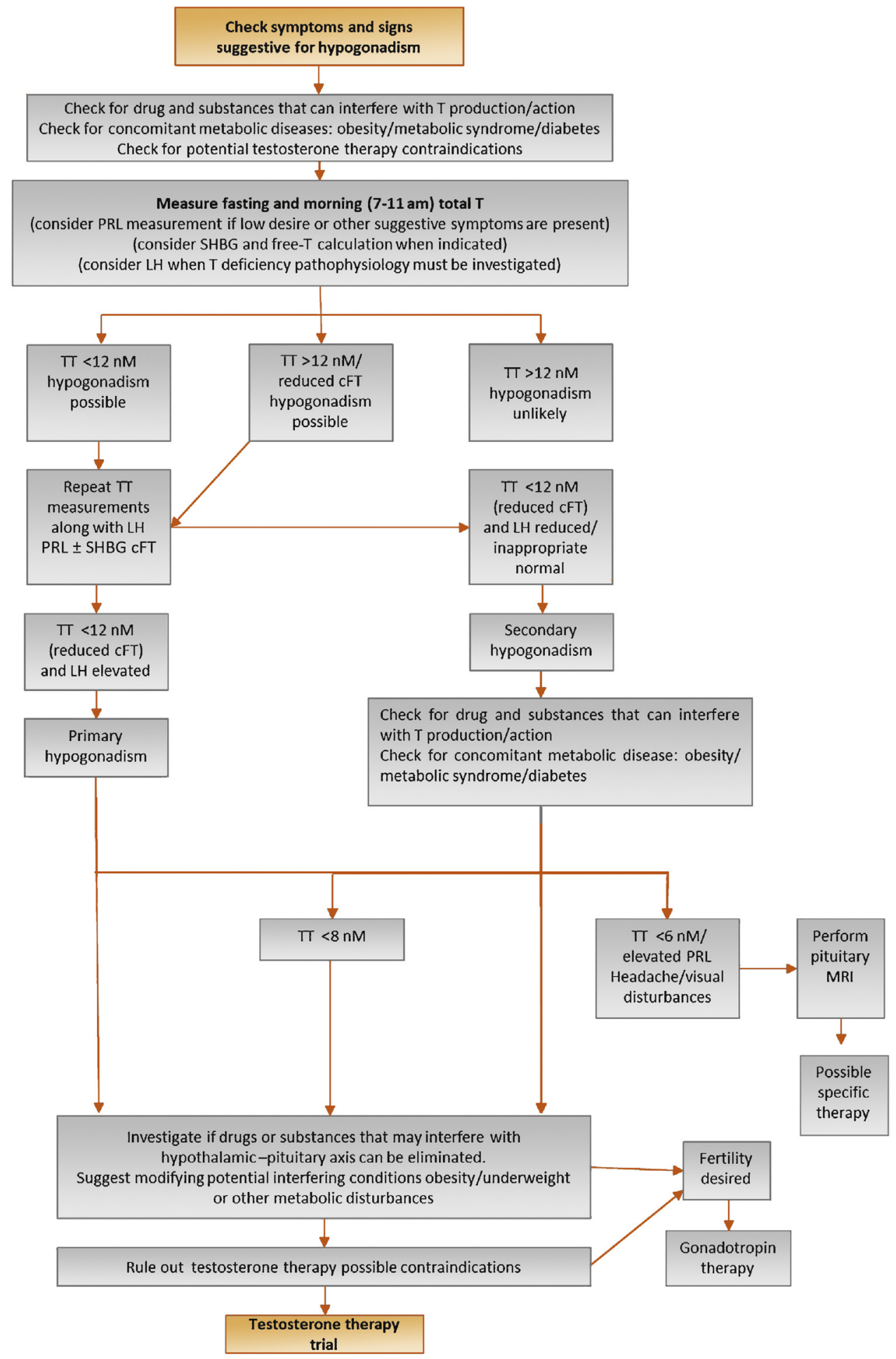

Fig. 1 - Diagnostic evaluation of late-onset hypogonadism. $\mathbf{c F T}=$ calculated free testosterone; $\mathrm{LH}=$ luteinising hormone; MRI = magnetic resonance imaging; $\mathbf{P R L}=$ prolactin; SHBG = sex hormone-binding globulin; $\mathrm{T}=$ testosterone; $\mathrm{TT}$ = total testosterone.

spectrometry (LC-MS/MS) represents the gold standard and most accurate method for sex steroid evaluation; however, standardised automated platform immune assays for total testosterone assessment demonstrate a good correlation with LC-MS/MS [21]. Conversely, available immunoassays are not able to provide an accurate estimation of free testosterone (fT); therefore, direct $\mathrm{fT}$ evaluation with these methods is not recommended and should be avoided [5]. Free testosterone can be derived from specific mathematical calculations taking into account serum sex hormone-binding globulin (SHBG) and albumin levels (http://www.issam.ch/freetesto.htm) [22]. 
Data derived from meta-analyses have shown that testosterone therapy is ineffective when baseline levels are above $12 \mathrm{nmol} / \mathrm{l}$ (3.5 ng/ml) [23]. Positive outcomes are documented when testosterone levels are below $12 \mathrm{nmol} / \mathrm{l}$ and higher in symptomatic patients with more severe forms of hypogonadism (testosterone $<8 \mathrm{nmol} / \mathrm{l}$ ). Hence, $12 \mathrm{nmol} / \mathrm{l}$ should be considered a threshold to start with testosterone therapy in the presence of hypogonadal symptoms (Table 1) $[23,24]$. In the presence of clinical conditions that may potentially interfere with SHBG levels (Supplementary Table 3 ), the evaluation of fT should be considered in order to better estimate actual testosterone levels (Fig. 1 and Table 1). Unfortunately, despite its potential clinical value [25], no validated thresholds for fT are available from clinical studies, and this represents an area of uncertainty; however, some data indicate that fT levels below $225 \mathrm{pmol} / \mathrm{l}(<6.5 \mathrm{ng} / \mathrm{dl})$ are associated with hypogonadal symptoms (Table 1 ) [7,26,27].

The determination of $\mathrm{LH}$ must be performed along with prolactin (PRL) when low total testosterone levels are detected, in order to define the underlying conditions correctly and exclude possible organic forms (Fig. 1 and Table 1). Owing to its negative influence on libido, PRL can also be considered as first-line screening in patients with reduced sexual desire. In addition, pituitary magnetic resonance imaging (MRI) scanning, as well as other pituitary hormone evaluation, is required in the presence of specific symptoms such as visual disturbances, headache, or when hyperprolactinemia is confirmed [28]. In addition, limited evidence suggests performing pituitary MRI also in cases of severe hypogonadism ( $<6 \mathrm{nmol} / \mathrm{l} ; 1.75 \mathrm{ng} / \mathrm{ml}$ ) with inadequate gonadotropin levels (Fig. 1 and Table 1) [28].

A number of self-reported questionnaires or structural interviews have been developed for the screening of hypogonadism [29]. Although these case-history tools have demonstrated clinical utility in supporting the biochemical diagnosis of hypogonadism, or in the assessment of testosterone therapy outcomes, their specificity remains relatively poor and they should not be used for systematic screening of hypogonadal men [30].

Since obesity is frequently associated with hypogonadism (mostly functional) [31,32], determination of body mass index (BMI) and measurement of waist circumference are strongly recommended in all individuals. Testicular and penile size, as well as the presence of sexual secondary characteristics, can provide useful information regarding overall androgen status. Finally, digital rectal examination (DRE) should be performed in all patients to exclude prostate abnormalities before testosterone therapy (any type) or support the suspicion of hypogonadism [33,34].

\subsubsection{Treatment of $\mathrm{LOH}$}

Patients with symptomatic hypogonadism without specific contraindications are suitable candidates for receiving testosterone therapy (Table 2). A detailed explanation of absolute and relative contraindications to testosterone therapy can be found in the complete EAU guidelines [3]. It should also be recognised that symptoms and signs of hypogonadism can be relatively similar independent of the
Table 2 - Main contraindications of testosterone therapy

\begin{tabular}{|c|c|}
\hline \multirow[t]{5}{*}{ Absolute contraindications } & $\begin{array}{l}\text { Locally advanced or metastatic } \\
\text { prostate cancer }\end{array}$ \\
\hline & Male breast cancer \\
\hline & $\begin{array}{l}\text { Men with an active desire to have } \\
\text { children }\end{array}$ \\
\hline & Haematocrit $\geq 54 \%$ \\
\hline & $\begin{array}{l}\text { Uncontrolled or poorly controlled } \\
\text { congestive heart failure }\end{array}$ \\
\hline \multirow[t]{3}{*}{ Relative contraindications } & $\begin{array}{l}\text { Severe lower urinary tract symptoms } \\
\text { (IPSS score }>19 \text { ) }\end{array}$ \\
\hline & Baseline haematocrit $48-50 \%$ \\
\hline & $\begin{array}{l}\text { Familial history for venous } \\
\text { thromboembolism }\end{array}$ \\
\hline
\end{tabular}

site of origin of the disease. Conversely, the age of onset of hypogonadism can deeply influence the clinical phenotype [35]. In patients with secondary hypogonadism, both fertility and testosterone normalisation can be achieved theoretically with an adequate treatment, whereas in primary hypogonadism, only testosterone therapy can be considered, which will suppress gonadotropins and endogenous testosterone secretion as well as spermatogenesis (Supplementary Table 1) [5,14]. Hence, testosterone therapy is contraindicated in individuals who desire fertility [36].

\subsubsection{Testosterone therapy outcomes}

3.1.4.1.1. Sexual dysfunction. Sexual concerns are the main symptoms of the hypogonadal patient [7]. A consistent body of evidence shows that testosterone therapy in hypogonadal men may have a beneficial effect on several aspects of sexual function (Fig. 1); in contrast, there is no evidence of benefits in using testosterone therapy for treating sexual dysfunction in eugonadal men (Table 3 ) $[23,24,37,38]$. The beneficial effect on sexual function seems to be more related to testosterone level normalisation rather than the specific testosterone formulations used $[33,39]$. Men with comorbidities such as diabetes usually show modest improvements in terms of sexual function after testosterone therapy and may potentially require concomitant phosphodiesterase type 5 inhibitors (PDE5Is) to improve effectiveness [5,38]. Overall, the specific beneficial effect derived from the combined use of testosterone therapy and PDE5Is is still not completely clear (Table 3) [24]. Similarly, information related to the combined use of testosterone therapy with other ED pharmacotherapies is lacking.

3.1.4.1.2. Body composition and metabolic profile. LOH is associated with a greater percentage of fat mass and a lower lean mass than testosterone-repleted men [40]. A substantial amount of published data have suggested that testosterone therapy reduces percentage body fat and increases lean mass $[41,42]$. However, it should be recognised that these results are mainly derived from registry and observational trials, which have important limitations due to the risk of 
Table 3 - Recommendations for testosterone therapy outcome

\begin{tabular}{lc}
\hline Recommendations & $\begin{array}{c}\text { Strength } \\
\text { rating }\end{array}$ \\
\hline $\begin{array}{l}\text { The use of testosterone therapy in eugonadal men is } \\
\text { not indicated. }\end{array}$ & Strong \\
$\begin{array}{l}\text { Use testosterone as first-line treatment in patients } \\
\text { with symptomatic hypogonadism and mild ED. }\end{array}$ & Strong \\
$\begin{array}{l}\text { Use combination of PDE5Is and testosterone therapy } \\
\text { in more severe forms of ED as it may result in better } \\
\text { outcomes. }\end{array}$ & Weak \\
$\begin{array}{l}\text { Use conventional medical therapies for severe } \\
\text { depressive symptoms and osteoporosis. }\end{array}$ & Strong \\
$\begin{array}{l}\text { Do not use testosterone therapy to improve body } \\
\text { composition, reduce weight, and benefit } \\
\text { cardiometabolic profile. }\end{array}$ & Weak \\
$\begin{array}{l}\text { Do not use testosterone therapy to improve cognition } \\
\text { vitality and physical strength in ageing men. }\end{array}$ & Strong \\
\hline ED = erectile dysfunction; PDE5Is = phosphodiesterase type 5 inhibitors. \\
\hline
\end{tabular}

selection bias for the nonrandom assignment of testosterone exposure (Table 3).

3.1.4.1.3. MetS and T2DM. A number of randomised controlled trials (RCTs) have shown that testosterone therapy might improve insulin resistance and hyperglycaemia, and lower cholesterol and low-density lipoprotein cholesterol [43]. Testosterone therapy in hypogonadal T2DM improved glycaemic control in some RCTs and registry trials [3]. A recent large placebo-controlled RCT, including 1007 patients with impaired glucose tolerance or newly diagnosed T2DM and total testosterone $<14 \mathrm{nmol} / \mathrm{l}$, showed that testosterone therapy for $2 \mathrm{yr}$ reduced the proportion of patients with T2DM regardless of a lifestyle programme [44]. Similarly, a previously published registry study reported that in men with T2DM, total testosterone $\leq 12.1 \mathrm{nmol} / \mathrm{l}$, and symptoms of hypogonadism, testosterone therapy was associated in time with improved glycaemic control and insulin resistance, and even remission of T2DM in one-third of the patients [45].

3.1.4.1.4. Mood and cognition. Several observational studies have documented a relationship between depressive symptoms, reduced quality of life $(\mathrm{QoL})$, and hypogonadism $[42,46]$, despite the specific relationship between hypogonadism and the incidence of depression still being unclear [46]. Only a few placebo-controlled RCTs have investigated the role of testosterone therapy in improving depressive symptoms. The largest meta-analysis of available studies, including 1890 hypogonadal (baseline total testosterone $<12 \mathrm{nmol} / \mathrm{l}$ or $\mathrm{fT}<225 \mathrm{pmol} / \mathrm{l})$ men from $27 \mathrm{RCTs}$, documented that the positive effect of testosterone therapy was particularly evident in patients with milder depressive symptoms [47]. Robust data on the effect of testosterone therapy on QoL are limited. Although recent meta-analyses suggest a significant effect of testosterone therapy over placebo, the magnitude is low and the heterogeneity high, therefore reducing the scientific value of the effect $[39,48]$. The role of testosterone therapy in patients with cognitive impairment is even more uncertain [49]. Data from the Sexual Function Trial of the Testosterone Trials
(TTrials; one of the largest placebo-controlled trials on testosterone therapy), which evaluated the effect of testosterone therapy in 493 individuals with age-associated memory impairment in order to assess possible improvement of several aspects of cognitive function, failed to demonstrate any beneficial effect of testosterone therapy in improving cognitive function (Table 3) [50].

3.1.4.1.5. Bone. The possible association between mild hypogonadism and osteopenia/osteoporosis is weak, whereas severe hypogonadism (total testosterone $<3.5 \mathrm{nmol} / \mathrm{l}$ ) is frequently associated with bone loss and osteoporosis, independent of patient age [51]. Although two independent meta-analyses and data derived from TTrials confirmed that testosterone therapy increased bone mass density in hypogonadal ageing men, particularly at the lumbar level $[50,52,53]$, available data are insufficient to determine the effect of testosterone therapy alone on the risk of bone fractures [51]. In addition, the use of testosterone therapy as an adjunct to antiresorptive treatment in hypogonadal patients at a high risk of fractures is not established. Therefore, antiresorptive therapy must be the first-choice treatment in hypogonadal men at a high risk for bone fractures. The combination of antiresorptive treatment and testosterone therapy should be offered only in conjunction with hypogonadal-related symptoms (Table 3 ).

3.1.4.1.6. Vitality and physical strength. The role of testosterone therapy in older men with mobility limitations remains unclear [50,54].

3.1.4.2. Testosterone therapy-medical preparations. Several testosterone formulations are available; a detailed explanation of available preparations can be found in the complete EAU guidelines [3]. The final choice should be based on the clinical situation, availability of testosterone formulations, and patient needs and expectations [55]. Table 4 provides guideline recommendations for the choice of treatment for LOH.

3.1.4.3. Testosterone therapy-safety and follow-up in hypogonadism management. As detailed, testosterone therapy is contraindicated in hypogonadal men seeking fertility treatment [36]. When secondary hypogonadism is present, gonadotropin therapy can maintain normal testosterone levels and restore sperm production [5]. Available meta-analyses did not find significant changes in lower urinary tract symptoms (LUTS) in men using testosterone therapy compared with placebo [56,57]. Likewise, according to the most recent literature, there are no grounds to discourage testosterone therapy in hypogonadal patients with benign prostatic hyperplasia (BPH)/LUTS. The only concern is related to patients with severe LUTS (International Prostate Symptom Score $>19$ ), as these patients are usually excluded from RCTs, therefore limiting the long-term safety data of testosterone therapy in this specific setting [33]. As for the association between circulating higher testosterone levels and prostate cancer (PCa), the most recent metaanalyses found no evidence of increased prostate-specific 
Table 4 - Recommendations for choice of treatment for late-onset hypogonadism

\begin{tabular}{lc}
\hline Recommendations & $\begin{array}{c}\text { Strength } \\
\text { rating }\end{array}$ \\
\hline $\begin{array}{l}\text { Treat, when indicated, organic causes of hypogonadism (eg, } \\
\text { pituitary masses, hyperprolactinemia, etc.). }\end{array}$ & Strong \\
$\begin{array}{l}\text { Improve lifestyle and reduce weight (eg, obesity); withdraw, } \\
\text { when possible, concomitant drugs that impair testosterone }\end{array}$ & Weak \\
production; treat comorbidity before starting testosterone & \\
therapy. & Strong \\
$\begin{array}{l}\text { Fully inform patients about expected benefits and adverse } \\
\text { effects of any treatment option. Select the testosterone } \\
\text { preparation in a joint decision process, only with fully }\end{array}$ & \\
informed patients. & Weak \\
$\begin{array}{l}\text { The aim of testosterone therapy is to restore serum } \\
\text { testosterone concentration to the average normal range for } \\
\text { young men. }\end{array}$ & \\
$\begin{array}{l}\text { Use testosterone gels rather than long-acting depot } \\
\text { administration when starting initial treatment, so that } \\
\text { therapy can be adjusted or stopped in case of treatment- } \\
\text { related adverse effects. }\end{array}$ & Weak \\
\hline
\end{tabular}

antigen (PSA) levels following testosterone therapy for no less than $1 \mathrm{yr}$ [58-60]. With regard to PCa survivors, because of the limited data available in the literature, safety in terms of the risk of recurrence and progression has not yet been established. Recently, meta-analyses suggested that testosterone therapy did not increase the risk of biochemical recurrence [60,61]. It is important to recognise that the vast majority of studies analysed included low-risk patients with a Gleason score of $<8$ [60]. In conclusion, while the EAU guidelines recommend to avoid testosterone administration in men with advanced PCa, insufficient longterm prospective data on the safety of androgen administration in PCa survivors [61] should prompt caution in choosing to treat symptomatic hypogonadal men in this setting. Patients should be fully counselled that the longterm effects of testosterone therapy in this setting are still unknown and require further investigation.

Published data show that $\mathrm{LOH}$ is associated with an increase in all-cause and CVD-related mortality [62]. There are no RCTs that provide a clear answer on whether testosterone therapy affects cardiovascular (CV) outcomes [63]. As a whole, as for major adverse cardiovascular events, current available data from interventional studies suggest that there is no increased risk with testosterone therapy with up to 3 yr of therapy [64-67]. An elevated haematocrit is the most common side effect of testosterone therapy $[68,69]$. There is no evidence that an increase of haematocrit up to and including 54\% causes any adverse effects on health. If the haematocrit exceeds $54 \%$, there is a testosterone-independent but weak associated rise in CV events and mortality [70], although there have been no specific studies including men with only testosterone-induced erythrocytosis. An elevated haematocrit in the absence of any comorbidities, or acute $\mathrm{CV}$ or venous thromboembolism can be managed by a reduction in testosterone dose-a change in formulation; conversely, if the elevated haematocrit is very high, it can be managed by venesection $(500 \mathrm{ml})$, even repeated if necessary, with usually no need to stop the testosterone therapy. There is also no clear
Table 5 - Recommendations on risk factors in testosterone treatment

\begin{tabular}{|c|c|}
\hline Recommendations & $\begin{array}{l}\text { Strength } \\
\text { rating }\end{array}$ \\
\hline $\begin{array}{l}\text { Fully counsel symptomatic hypogonadal men who have } \\
\text { surgically treated for localised PCa and who are currently } \\
\text { without evidence of active disease considering testosterone } \\
\text { therapy, emphasising the benefits and lack of sufficient } \\
\text { safety data on long-term follow-up. }\end{array}$ & Weak \\
\hline $\begin{array}{l}\text { Restrict treatment to patients with a low risk for recurrent } \\
\text { PCa (ie, preoperative PSA }<10 \mathrm{ng} / \mathrm{ml} \text {, Gleason score }<7 \\
\text { [International Society for Urological Pathology grade } 1 \text { ], cT1- } \\
\text { 2a), }{ }^{\text {a }} \text { and treatment should start after at least } 1 \mathrm{yr} \text { of follow- } \\
\text { up with PSA level }<0.01 \mathrm{ng} / \mathrm{ml} \text {. }\end{array}$ & Weak \\
\hline $\begin{array}{l}\text { Safety data on the use of testosterone therapy in men treated } \\
\text { for breast cancer are unknown. }\end{array}$ & Strong \\
\hline $\begin{array}{l}\text { Assess CV risk factors before commencing testosterone } \\
\text { therapy. }\end{array}$ & Strong \\
\hline $\begin{array}{l}\text { Assess men with known CVD for CV symptoms before } \\
\text { testosterone therapy and with close clinical assessment and } \\
\text { evaluation during treatment. }\end{array}$ & Strong \\
\hline $\begin{array}{l}\text { Treat men with hypogonadism and pre-existing CVD, venous } \\
\text { thromboembolism, or chronic cardiac failure, who require } \\
\text { testosterone therapy with caution, by careful clinical } \\
\text { monitoring and regular measurement of haematocrit (not } \\
\text { exceeding 54\%) and testosterone levels. }\end{array}$ & Weak \\
\hline $\begin{array}{l}\text { Exclude a family history of venous thromboembolism before } \\
\text { starting testosterone therapy. }\end{array}$ & Strong \\
\hline $\begin{array}{l}\text { Monitor testosterone and haematocrit at } 3,6 \text {, and } 12 \text { mo } \\
\text { after testosterone therapy initiation, and thereafter annually. } \\
\text { Haematocrit }>54 \% \text { should require testosterone therapy } \\
\text { withdrawal and phlebotomy. Reintroduce testosterone } \\
\text { therapy at a lower dose once the haematocrit has normalised } \\
\text { and consider switching to topical testosterone preparations. }\end{array}$ & Strong \\
\hline \multicolumn{2}{|c|}{$\begin{array}{l}\mathrm{CV}=\text { cardiovascular; } \mathrm{CVD}=\text { cardiovascular disease; } \mathrm{EAU}=\text { European } \\
\text { Association of Urology; } \mathrm{PCa}=\text { prostate cancer; } \mathrm{PSA}=\text { prostate-specific } \\
\text { antigen. } \\
\text { a As for EAU risk groups for biochemical recurrence of localised or locally } \\
\text { advanced prostate cancer (see EAU guidelines } 2020 \text { on prostate cancer). }\end{array}$} \\
\hline
\end{tabular}

evidence that testosterone therapy can result in the onset or worsening of sleep apnoea.

Table 5 summarises the recommendations on risk factors for testosterone therapy.

Testosterone therapy alleviates symptoms and signs of hypogonadism in men. In terms of follow-up, testosterone therapy in hypogonadal men has been proved to be effective in alleviating symptoms and signs in a specific timedependent manner [50]. Hence, the first evaluation should be planned after 3 mo of treatment. Further evaluation may be scheduled at 6 or $12 \mathrm{mo}$, according to patient characteristics, as well as results of biochemical testing. Table 6 summarises the clinical and biochemical parameters that should be monitored during testosterone therapy.

\subsection{Erectile dysfunction}

\subsubsection{Definition and epidemiology of $E D$}

ED is defined as the persistent inability to attain and maintain an erection sufficient to permit satisfactory sexual performance [71]. ED may affect psychosocial health and have a significant impact on the QoL of patients and their partners. ED is commonly classified into three groups based on aetiology. These include organic, psychogenic, and mixed 
Table 6 - Clinical and biochemical parameters to be checked during testosterone therapy

\begin{tabular}{|c|c|c|c|c|c|}
\hline \multirow[t]{2}{*}{ Parameters } & \multicolumn{3}{|c|}{ Year 1 of treatment } & \multicolumn{2}{|c|}{ After year 1 of treatment } \\
\hline & Baseline & $3 \mathrm{mo}$ & $6 / 12 \mathrm{mo}$ & Annually & $18-24 \mathrm{mo}$ \\
\hline \multicolumn{6}{|l|}{ Clinical } \\
\hline Symptoms & $x$ & $x$ & $x$ & $x$ & \\
\hline \multicolumn{6}{|l|}{ BMI } \\
\hline Waist circumference & $x$ & $x$ & $x$ & $x$ & \\
\hline DRE & $x$ & $x$ & $x$ & $x$ & \\
\hline Blood pressure & $x$ & $x$ & $x$ & $x$ & \\
\hline
\end{tabular}

ED. However, this classification should be used with caution as most cases are actually of mixed aetiology. Therefore the use of the term "primary organic" or "primary psychogenic" has been suggested.

Epidemiological data have shown a high prevalence and incidence of ED worldwide [72]; detailed available data on ED incidence and prevalence can be found in the complete EAU guidelines [3].

There is established evidence that the presence of ED increases the risk of future CV events including myocardial infarction, cerebrovascular events, and all-cause mortality, with a trend towards an increased risk of CV mortality [73]. Therefore, ED can be an early manifestation of coronary artery and peripheral vascular disease, and should not be regarded only as a $\mathrm{QoL}$ issue, but also as a potential warning sign of CVD [73-75].

\subsubsection{Risk factors for $E D$}

ED is associated with unmodifiable and modifiable common risk factors, including age, diabetes mellitus, dyslipidaemia, hypertension, CVD, BMI/obesity/waist circumference, MetS, hyperhomocysteinemia, lack of exercise, and smoking $[73,74,76]$. Furthermore, an association between ED status and pharmacotherapeutic agents for CVD (eg, thiazide diuretics and $\beta$-blockers, except nebivolol) exerts detrimental effects on erectile function, whereas other drugs (ie, angiotensin-converting enzyme inhibitors, angiotensin receptor blockers, and calcium channel blockers) have neutral or even beneficial effects [3,71,77]. Atrial fibrillation, hyperthyroidism, vitamin D deficiency, hyperuricaemia, depression, chronic renal disease, rheumatic disease, and COPD have also been associated with ED [3]. Available data do not confirm a clear association between ED and hypothyroidism [78-80] and hyperprolactinemia [8082]. Further epidemiological data have also highlighted other potential risk factors associated with ED, including sleep disorders, obstructive sleep apnoea, psoriasis, gouty arthritis and ankylosing spondylitis, nonalcoholic fatty liver disease, other chronic liver disorders, chronic periodontitis, open-angle glaucoma, inflammatory bowel disease, chronic fatigue syndrome, and allergic rhinitis [3]. Insufficient data are currently available to correlate a primarily organic or a primarily psychogenic ED problem with SARS-CoV-2 infection-associated disease (COVID-19) [83,84]. A number of studies have shown that lifestyle modification, including physical activity, weight loss, and pharmacotherapy for CVD risk factors, may be of help in improving sexual function in men with ED [85,86]. Meta-analytic data reveal a positive effect of lipid-lowering therapy with statins on erectile function [87].

ED is also frequently associated with a number of urological conditions and procedures $[3,88]$. Epidemiological studies have demonstrated consistent evidence for an association between LUTS/BPH and sexual dysfunction, regardless of age, other comorbidities, and lifestyle factors [89]. Regardless of the technique used, surgery for BPH/ LUTS had no significant impact on erectile function. In fact, even an improvement was found depending on the degree of improvement of urinary symptoms [90,91]. An association between ED and chronic prostatitis/chronic pelvic pain syndrome, and bladder pain syndrome/interstitial cystitis has been confirmed, mostly in younger men [92,93]. An increased risk of ED is reported following transrectal ultrasound (TRUS)-guided prostate biopsy [94] and after open urethroplasty, especially for correction of posterior strictures [3,95]. Pelvic surgery, especially for oncological disease (eg, radical prostatectomy or RP [96,97] or radical cystectomy [98], and colorectal surgery [99]), may have a negative impact on erectile function and overall sexual health [3]. The most relevant causal factor is a lesion (any) occurring to the neurovascular bundles that control the complex mechanism of the cavernous erectile response, the preservation (either partial or complete) of which during surgery constitutes the so-called nerve-sparing (NS) approach [100]. Thus, surgery resulting in damage of the neurovascular bundles will result in ED, although NS approaches have been adopted over the last few decades [100]. A significant amount of data have been reported, outlining various treatment outcomes in men operated with a variety of NS approaches. In terms of the effects of surgical interventions (eg, robot-assisted RP vs other types of surgery), data are still conflicting [3,101-105]. Of note, despite the advancements in surgical techniques and the advent of minimally invasive approaches, the rates of postRP ED are still high and ranging between 25\% and 75\% [3,101-105]. Even nonsurgical treatments of PCa (ie, radiotherapy and brachytherapy) can be associated with significant impairment of erectile function [106,107]. Overall, potential therapeutic options in patients with clinically localised PCa (eg, high-intensity focused ultrasound [US], cryoablation of the prostate [cryotherapy], focal padeliporfin-based vascular-targeted photodynamic therapy, and focal radiation therapy by brachytherapy or CyberKnife) have been shown to have a less negative impact on erectile 
function, although all these treatment approaches lack robust long-term oncological outcomes, and prospective RCTs are needed to compare functional and oncological outcomes between these surgical treatment modalities $[3,108]$. The concept of an active surveillance (AS) strategy for the treatment of PCa was developed to avoid overtreatment of nonsignificant localised low-risk diseases, while limiting potential functional side effects (including ED). However, it is interesting that data suggest that even AS may have a detrimental impact on erectile function (and sexual well-being as a whole) $[3,109]$.

\subsubsection{Diagnostic evaluation (basic work-up)}

3.2.3.1. Medical and sexual history. Figure 2 lists the minimal diagnostic evaluation (basic work-up) in patients with ED. The first step in evaluating ED is always a detailed medical and sexual history of patients and, when available, their partners [110]. The sexual history must include information about previous and current sexual relationships, current emotional status, onset and duration of the erectile problem, and previous consultations and treatments. The sexual health status of the partner(s), when available, can also be useful. A detailed description should be made of the rigidity and duration of both sexually stimulated and morning erections and of problems with sexual desire, arousal, ejaculation, and orgasm [111]. Validated psychometric questionnaires (such as the International Index of Erectile Function or IIEF [112] or its shortened version, ie, Sexual Health Inventory for Men [SHIM]) or structured interviews help assess the different sexual function domains (ie, sexual desire, erectile function, orgasmic function, intercourse satisfaction, and overall satisfaction), as well as the potential impact of a specific treatment modality. Psychometric analyses also support the use of the Erectile Hardness Score (EHS) [113] for the assessment of penile rigidity in practice and in clinical trial research, or the

Patient with ED (self-reported)

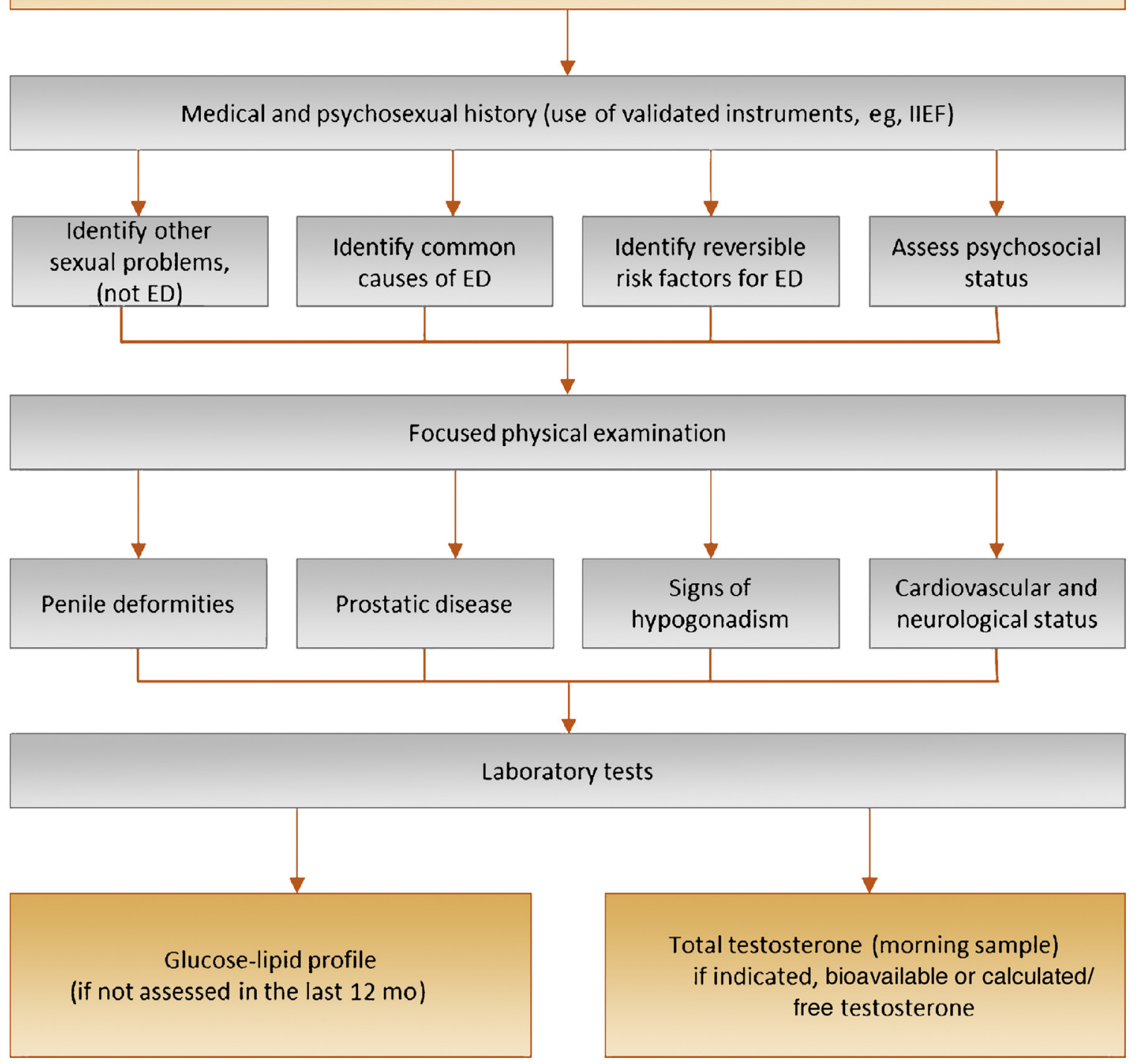

Fig. 2 - Minimal diagnostic evaluation (basic work-up) in patients with ED. ED = erectile dysfunction; IIEF = International Index of Erectile Function. 
Beck Depression Inventory [114] in cases of depressive mood. Patients should always be screened for symptoms of possible hypogonadism, as well as for LUTS [3].

Of clinical relevance, patients who seek treatment for sexual dysfunction have a high prevalence of CVDs. ED increases significantly the risk of CVD, coronary heart disease, and stroke [115,116]. Furthermore, ED is an independent predictor of incident atrial fibrillation [117]. All these increase mortality and are probably independent of conventional CV risk factors [73]. The EAU guidelines for diagnosing and treating men with ED have been adapted from previously published recommendations from the Princeton Consensus conferences on sexual dysfunction and cardiac risk [118]. Accordingly, patients with $\mathrm{ED}$ can be stratified into three CV risk categories, which can be used as the basis for a treatment algorithm for initiating or resuming sexual activity (Fig. 3).

3.2.3.2. Physical examination. Every patient must undergo a physical examination focused on the genitourinary, endocrine, vascular, and neurological systems [119]. A physical examination may reveal unsuspected diagnoses, such as
Peyronie's disease (PD), premalignant or malignant genital lesions, prostatic enlargement or irregularity/nodularity, or signs and symptoms suggestive of hypogonadism (ie, small testes, alterations in secondary sexual characteristics, etc.). Overall, assessing previous or concomitant penile abnormalities (eg, hypospadias, congenital curvature, or PD with preserved rigidity) during the medical history and the physical examination is mandatory. Blood pressure and heart rate should be measured if these have not been assessed in the previous 3-6 mo. Likewise, either a BMI calculation or a waist circumference measurement should be undertaken to assess patients for comorbid conditions (Fig. 2).

3.2.3.3. Laboratory testing. Laboratory testing must be tailored to the patient's complaints and risk factors. Patients should undergo fasting blood glucose, HbA1c, and lipid profile tests if these have not been assessed in the previous $12 \mathrm{mo}$. Hormonal tests should include an early morning total testosterone in a fasting state. The bioavailable or calculated fT value can be used to corroborate total testosterone measurements after considering SHBG evaluation. Addi-

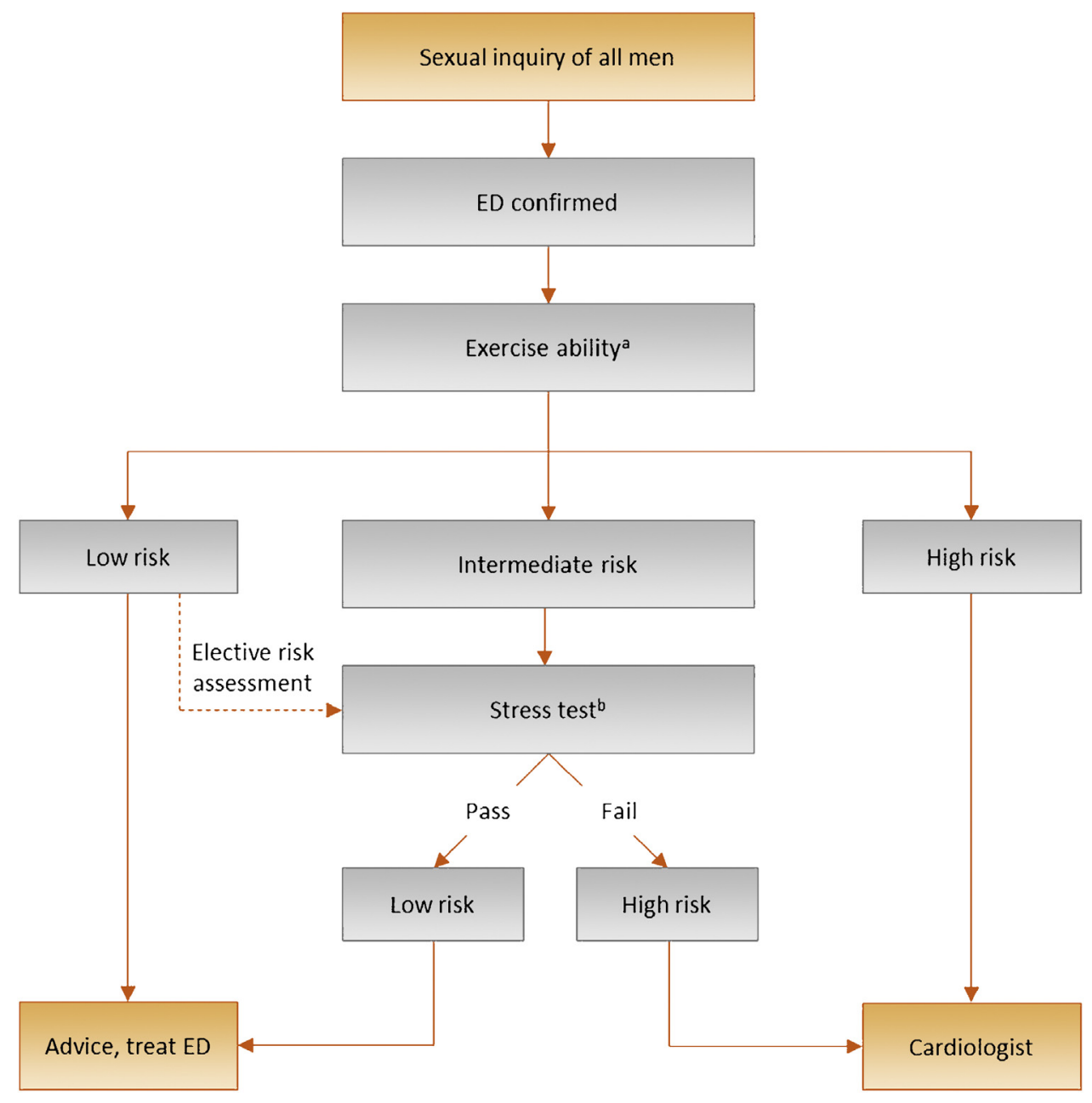

Fig. 3 - Treatment algorithm for determining level of sexual activity according to cardiac risk in ED (based on the third Princeton Consensus). $\mathrm{ED}=$ erectile dysfunction. ${ }^{\mathrm{a}}$ Sexual activity is equivalent to walking 1 mile on the flat in 20 min or briskly climbing two flights of stairs in $10 \mathrm{~s}$. ${ }^{b}$ Sexual activity is equivalent to 4 min of the Bruce treadmill protocol. 
Table 7 - Recommendations for the diagnostic evaluation of erectile dysfunction

\begin{tabular}{lc}
\hline Recommendations & $\begin{array}{c}\text { Strength } \\
\text { rating }\end{array}$ \\
\hline $\begin{array}{l}\text { Take a comprehensive medical and sexual history in every } \\
\text { patient presenting with ED. Consider psychosexual } \\
\text { development, including life stressors, cultural aspects, and } \\
\text { cognitive/thinking style of the patient regarding their sexual }\end{array}$ & Strong \\
performance. & Strong \\
$\begin{array}{l}\text { Use a validated questionnaire related to ED to assess all } \\
\text { sexual function domains (eg, IIEF) and the effect of a specific } \\
\text { treatment modality. }\end{array}$ & Strong \\
$\begin{array}{l}\text { Include a focused physical examination in the initial } \\
\text { assessment of men with ED to identify underlying medical } \\
\text { conditions and comorbid genital disorders that may be } \\
\text { associated with ED. }\end{array}$ & \\
$\begin{array}{l}\text { Assess routine laboratory tests, including glucose and lipid } \\
\text { profile and total testosterone, to identify and treat any }\end{array}$ & Strong \\
reversible risk factors and lifestyle factors that can be \\
modified.
\end{tabular}

tional laboratory tests may be considered in selected patients with specific signs and associated symptoms (eg, PSA), PRL, and LH [120]). Although physical examination and laboratory evaluation of most men with ED may not reveal the exact diagnosis, clinical and biochemical evaluations present an opportunity to identify comorbid conditions [119].

\subsubsection{Diagnostic evaluation (advanced work-up)}

Most patients with ED can be managed on the basis of medical and sexual history; conversely, some patients may need specific diagnostic tests (Supplementary Table 4).

3.2.4.1. Nocturnal penile tumescence and rigidity test. For the nocturnal penile tumescence and rigidity (NPTR) test, nocturnal monitoring devices are used to measure the number of erectile episodes, tumescence (circumference change by strain gauges), maximal penile rigidity, and duration of nocturnal erection(s) [121-123]. NPTR monitoring is considered an additional test for even more objectively differentiating between organic and psychogenic ED (patients with psychogenic ED usually have normal findings in the NPTR test), but many potential confounding factors (eg, situational) may limit its routine use solely for diagnostic purposes [121,124].

3.2.4.2. Intracavernous injection test. The intracavernous injection test gives limited information about the vascular status; overall, the test is inconclusive as a diagnostic procedure, and a duplex Doppler study of the penis should be requested, if clinically warranted.

3.2.4.3. Dynamic duplex US of the penis. Dynamic duplex US of the penis is a test specifically aimed to study the haemodynamic pathophysiology of erectile function [125]. Therefore, in clinical practice, it is usually applied in those conditions where a potential vasculogenic aetiology of ED (eg, diabetes mellitus, renal transplantation, multiple concomitant CV risk factors and/or overt peripheral vascular disease, poor responders to oral therapy, etc.) is suspected [3]. Recent data have suggested that duplex scanning as a haemodynamic study may be better at tailoring therapy for ED, such as for low-intensity shockwave therapy (LI-SWT) and for diagnosing vasculogenic ED [126]. Further vascular investigation is unnecessary if a duplex US examination is normal.

3.2.4.4. Arteriography and dynamic infusion cavernosometry or cavernosography. Pudendal arteriography should be performed only in patients who are being considered for penile revascularisation [127]. Nowadays, dynamic infusion cavernosometry or cavernosography are infrequently used diagnostic tools aimed at diagnosing venogenic ED [3].

3.2.4.5. Psychiatric and psychosocial assessment. When clinically indicated, patients with psychiatric disorders should be referred to a psychiatrist [3]. In younger patients ( $<40 \mathrm{yr})$ with long-term primary ED, psychiatric assessment may be helpful before any clinical assessment is carried out. Mental health issues are frequently comorbid with ED; this is most evident for depression- and anxiety-related disorders, but may also include transitory states of altered mood (ie, dysfunctional affective states resulting from a specific life stressor) [3,128].

Table 7 details the recommendations for the diagnostic evaluation of patients presenting with ED.

\subsubsection{Treatment of ED}

ED can be treated successfully with a number of therapeutic options, but it cannot be cured. The only exceptions are psychogenic ED, post-traumatic arteriogenic ED in young patients, and hormonal causes (eg, hypogonadism) $[3,120]$, which can potentially be cured with specific treatments. Most men with ED will be treated with therapeutic options that are not cause specific. Based on the currently available evidence and the consensus of the panel, a novel comprehensive therapeutic and decision-making algorithm for treating ED has been presented (Fig. 4). This novel treatment algorithm was discussed extensively within the guideline panel as an alternative to the traditional threelevel concept, in order to better tailor personalised therapy to individual patients, according to invasiveness, tolerability, and effectiveness of the different therapeutic options, along with patients' needs and expectations. In this context, patients should be counselled fully with respect to all available treatment modalities.

ED may be associated with modifiable or reversible risk factors, including lifestyle or drug-related factors [3]. These factors may be modified either before or at the same time as specific therapies are used. Likewise, ED may be associated with concomitant and underlying conditions (such as endocrine disorders and metabolic disorders-eg, diabetes, and some CV problems-eg, hypertension), which should always be well controlled as the first step of any ED treatment [129]. Major clinical potential benefits of lifestyle 


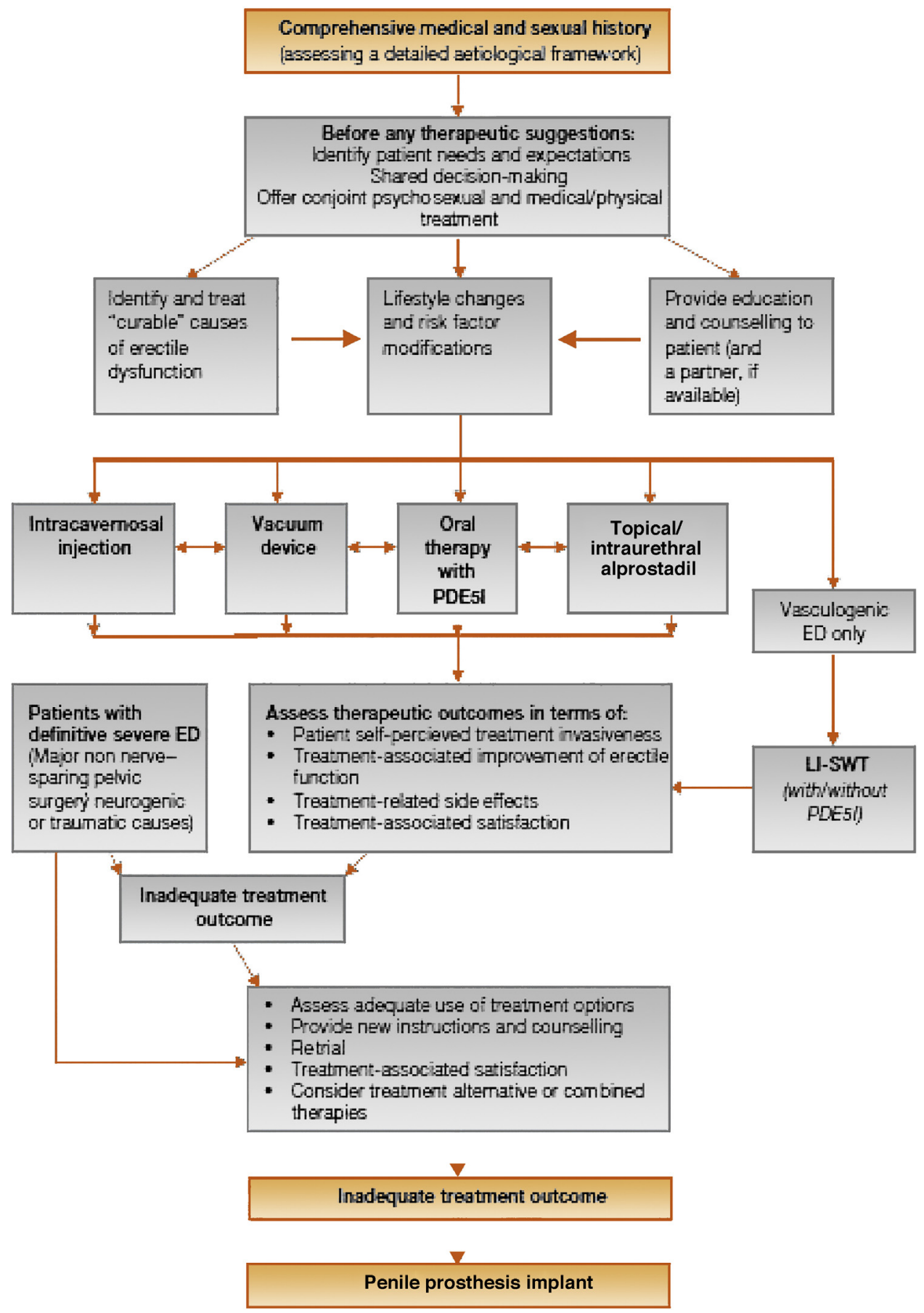

Fig. 4 - Management algorithm for erectile dysfunction. ED = erectile dysfunction; LI-SWT = low-intensity shockwave therapy; PDE5I = phosphodiesterase type 5 inhibitor.

changes may be achieved in men with specific comorbid CV or metabolic disorders, such as diabetes or hypertension [129]. An educational intervention is often the first approach to sexual dysfunction and consists of informing patients about the psychological processes involved in the individual's sexual response, in ways they can understand. This first-level approach was shown to favour sexual satisfaction in men with ED [130].
3.2.5.1. Oral pharmacotherapy for ED. Four potent selective PDE5Is have currently been approved by the European Medicines Agency (EMA) for the treatment of ED (ie, sildenafil, tadalafil, vardenafil, and avanafil) [3,129]. A detailed summary of their key pharmacokinetic data, along with their effectiveness and safety profiles can be found in the EAU guidelines, which also details potential strategies to manage nonresponders to PDE5Is, thus including combina- 
tion therapies [3]. Overall, since they are not initiators of erection, PDE5Is require sexual stimulation to facilitate an erection. Efficacy is defined as an erection, with rigidity, sufficient for satisfactory intercourse. To date, no data are available from double- or triple-blind multicentre studies comparing the efficacy and/or patient preference for the four available PDE5Is. The choice of drug will depend on the frequency of intercourse (occasional use or regular therapy, three to four times weekly) and the patient's personal experience. Patients need to know whether a drug is shortor long-acting, its possible disadvantages, and how to use it $[3,129]$. Most frequent treatment-related side effects (ie, headache, flushing, dyspepsia, nasal congestion, dizziness, abnormal vision, back pain, and myalgia) are generally mild in nature and self-limited [129].

3.2.5.1.1. CV safety. Clinical trial results for the four PDE5Is and postmarketing data of sildenafil, tadalafil, and vardenafil have demonstrated no increase in myocardial infarction rates in patients receiving PDE5Is, as part of either RCTs or open-label studies, or compared with expected rates in agematched male populations [131]. None of the PDE5Is had an adverse effect on total exercise time or time to ischaemia during exercise testing in men with stable angina [131]. Chronic or on-demand use is well tolerated with a similar safety profile. The prescription of all PDE5Is in patients with CVD or in those with a high CV risk should be based on the recommendations of the third Princeton Consensus Panel [118].

In general, the adverse event profile of a PDE5I is not worsened by a background of antihypertensive medication, even when the patient is taking several antihypertensive agents. Coadministration of PDE5Is with antihypertensive agents (eg, angiotensin-converting enzyme inhibitors, angiotensin-receptor blockers, calcium blockers, $\beta$-blockers, and diuretics) may result in small additive decreases in blood pressure, which are usually minor [118]. All PDE5Is show some interaction with $\alpha$-blockers. A recent metaanalysis concluded that a concomitant treatment with $\alpha$-blockers and PDE5Is may produce changes in haemodynamic parameters, but it does not increase the rate of adverse events due to hypotension [132]. In everyday clinical practice, a patient presenting for ED should be stable on one medication before starting a PDE5I, and the use of uroselective $\alpha$-blockers should strongly be preferred. Absolute contraindication to PDE5Is is represented by patients who are using any form of organic nitrate (eg, nitroglycerine, isosorbide mononitrate, and isosorbide dinitrate) or nitric oxide donors (eg, other nitrate preparations used to treat angina, such as nicorandil, an antianginal vasodilator drug that acts by increasing nitric oxide bioavailability and opening of the $\mathrm{K}_{\mathrm{ATP}}$ channel, as well as amyl nitrite or amyl nitrate such as "poppers" that are used for recreation) $[3,133,134]$.

3.2.5.2. Topical/intraurethral alprostadil. The vasoactive agent alprostadil can be administered per urethra with two different formulations. The first compound is the topical route using a cream that includes a permeation enhancer in order to facilitate absorption of alprostadil (200 and $300 \mu \mathrm{g})$ via the urethral meatus [135]. Clinical data in patients with mild-to-severe ED are still limited. Side effects include penile erythema, penile burning, and pain that usually resolve within $2 \mathrm{~h}$ of application. Systemic side effects (eg, dizziness and hypotension) are very rare. The second method of delivery is by the intraurethral insertion of a specific formulation of alprostadil (125-1000 $\mu \mathrm{g})$ in a medicated pellet (MUSE). Topical alprostadil (Vitaros) at the dose of $300 \mu \mathrm{g}$ is available in some European countries [3]. Recently a randomised cross-over clinical trial showed that, compared with the standard administration route, direct delivery of the drug within the urethral meatus is able to increase the level of treatment efficacy and confidence among patients, without increasing the incidence of side effects [136].

3.2.5.3. Intracavernous injection therapy. Intracavernous administration of vasoactive drugs was the first medical treatment introduced for ED. According to invasiveness, tolerability, effectiveness, and patients' expectations (Fig. 4), patients may be offered intracavernous injections. Overall, the success rate is high (85\%) [137]. Alprostadil (Caverject and Edex/Viridal) was the first and only drug approved for intracavernous treatment of ED [138]. Intracavernous alprostadil is most efficacious as a monotherapy at a dose of 5-40 $\mu \mathrm{g}$ (of note, $40 \mu \mathrm{g}$ dose may be offered off-label in some European countries). An office-training programme is required for the patient to learn the injection technique. The use of an automatic pen that avoids a view of the needle may be useful to resolve fear of penile puncture and simplifies the technique. Efficacy rates for intracavernous alprostadil of $>70 \%$ have been found in the general ED population, as well as in patient subgroups (eg, men with diabetes or CVD), with reported satisfaction rates of 8793.5\% in patients and $86-90.3 \%$ in partners after the injections, respectively $[139,140]$. Complications of intracavernous alprostadil include penile pain (1-11\%), excessively prolonged undesired erections, priapism (0.25-1\%), and persisting (tunical) fibrosis (5-7\%) [137,141]. Systemic side effects (ie, mild hypotension) are uncommon. Contraindications include men with a history of hypersensitivity to alprostadil, men at risk of priapism, and men with bleeding disorders. Careful counselling of patients during the officetraining phase as well as close follow-up is important in addressing patient withdrawal from an intracavernous injection programme [138].

3.2.5.4. Low-intensity shockwave therapy. The use of LI-SWT has increasingly been proposed as a treatment for vasculogenic ED over the last decade [142], being the only currently marketed treatment that might offer a cure, which is the most desired outcome for most men suffering from ED [126]. Overall, several single-arm trials have shown benefit of LI-SWT in patient-reported erectile function scores, but data from prospective randomised trials are conflicting, and many questions remain to be answered especially because of the heterogeneity in shockwave generators (ie, electrohydraulic, electromagnetic, piezoelectric, and electropneu- 
matic), type of shockwaves delivered (ie, focused, linear, semifocused, and unfocused), set-up parameters (eg, energy flux density and number of pulses per session), and treatment protocols (ie, duration of treatment course, number of sessions per week, total number of shockwave pulses delivered, and penile sites of application) [143]. As a whole, most of the studies suggest that LI-SWT can significantly increase the IIEF and EHS, especially in patients with mild vasculogenic ED, although this improvement appears modest [126]; indeed, a pooled data analysis of RCTs has shown a mean IIEF-EF score improvement from baseline ranging from 2 to 4 points [126]. Moreover, few studies have shown an improvement in terms of penile haemodynamic parameters after LI-SWT, with a metaanalysis showing a mean peak systolic velocity improvement of 4.12 (95\% confidence interval: 2.3-5.9) after treatment [143], but the clinical meaning of this improvement remains unclear [143]. Likewise, data suggest that LISWT could ameliorate erection quality even in patients with severe ED who are either nonresponders or inadequate responders to PDE5Is $[144,145]$, thus reducing the immediate need for more invasive treatments. Further clarity is also needed in defining treatment protocols that can result in greater clinical benefits [146]. As a whole, according to the available data and the novel treatment decision algorithm, LI-SWT may be offered to patients with vasculogenic ED, although they should be counselled fully before treatment.

3.2.5.5. Vacuum erection devices. Published data report that the efficacy of vacuum erection devices, in terms of erections satisfactory for intercourse, is as high as $90 \%$, regardless of the cause of $E D$, and satisfaction rates range between $27 \%$ and 94\% [147]. The most common adverse events include pain, inability to ejaculate, petechiae, bruising, and numbness. Serious adverse events (skin necrosis) can be avoided if patients remove the constriction ring within $30 \mathrm{~min}$. Vacuum erection devices are contraindicated in patients with bleeding disorders or those on anticoagulant therapy [127,147].

3.2.5.6. Hormonal treatment. When clinically indicated [3,5], testosterone therapy (intramuscular or transdermal) can be considered for men with low or low-normal testosterone levels and concomitant problems with their sexual desire, erectile function, and dissatisfaction derived from intercourse and overall sexual life. The advice of an endocrinologist should be sought for managing patients with certain hormonal abnormalities or endocrinopathies [120].

3.2.5.7. Psychosexual counselling and therapy. For patients with a recognised psychological problem $[3,148]$, psychosexual therapy may be given either alone or with another therapeutic approach in order to improve couple's sexual satisfaction and partner's sexual function. Despite this psychological treatment including different modalities (eg, training of sexual skills, marital therapy, and psychosexual education) [130], cognitive and behaviour therapy (CBT), including group or couple format, has been recommended [149]. The CBT approach combined with the medical treatment for ED has received empirical support and is considered an optimal procedure [149].

3.2.5.8. Vascular surgery for ED. In young patients with pelvic or perineal trauma, surgical penile revascularisation has a $60-$ 70\% long-term success rate [127]. The stenosis must be confirmed by penile pharmacoarteriography. Corporeal veno-occlusive dysfunction is a contraindication to revascularisation and must be excluded by dynamic infusion cavernosometry or cavernosography [3]. Venous ligation surgery for veno-occlusive dysfunction is no longer recommended because of poor long-term results [3].

3.2.5.9. Penile prostheses. Surgical implantation of a penile prosthesis may be considered in patients who (1) are not suitable for different pharmacotherapies or prefer a definitive therapy and (2) do not respond to pharmacological therapies (Fig. 4). The vast majority of men receiving penile prosthesis for ED have organic causes, with vascular disease, diabetes, and previous pelvic surgery/trauma being most common $[150,151]$. The two currently available classes of penile implants include inflatable (two and three pieces) and semirigid devices (malleable, mechanical, and soft flexible) [3]. There are two main surgical approaches for penile prosthesis implantation: penoscrotal and infrapubic. A recent systematic review comparing the satisfaction and complication rates of the different surgical approaches showed that there is no specific advantage between the two, but rather it is recommended that the surgeon has knowledge of both techniques and is capable of tailoring the incision strategy for complex cases [152]. Regardless of the indication, prosthesis implantation has one of the highest satisfaction rates among the treatment options for ED with appropriate counselling $[3,153,154]$. Structured psychosexual counselling may improve sexuality and sexual well-being in both patients and their partners after penile implant surgery [155]. A detailed summary of the types of prostheses currently available, along with their effectiveness and complication profiles, can be found in the EAU guidelines [3]. Of note, currently there are also no head to head studies comparing the different manufacturers' implants, demonstrating superiority of one implant type over another [156].

Table 8 details the recommendations for the treatment of patients presenting with ED.

\subsubsection{Follow-up in patients with $E D$}

Follow-up is important in order to assess efficacy and safety of the treatment provided. It is also essential to assess patient satisfaction since successful treatment for ED goes beyond efficacy and safety. Physicians must be aware that there is no single treatment that fits all patients or all situations, as described in detail in the previous section.

\subsection{Disorders of ejaculation}

Ejaculation is a complex physiological process that is composed of emission and expulsion processes and is mediated by neurological and hormonal pathways. Any 
Table 8 - Recommendations for the treatment of erectile dysfunction

\begin{tabular}{|c|c|}
\hline Recommendations & $\begin{array}{l}\text { Strength } \\
\text { rating }\end{array}$ \\
\hline $\begin{array}{l}\text { Assess all patients for inadequate/incorrect information } \\
\text { about the mechanism of action and the ways in which drugs } \\
\text { should be taken, as they are the main causes of a lack of } \\
\text { response to PDE5Is. }\end{array}$ & Weak \\
\hline $\begin{array}{l}\text { Use CBT as a psychological approach (include the partner) } \\
\text { combined with medical treatment to maximise treatment } \\
\text { outcomes. }\end{array}$ & Strong \\
\hline $\begin{array}{l}\text { Discuss with patients undergoing RP (any technique) about } \\
\text { the risk of sexual changes other than ED, including libido } \\
\text { reduction, changes in orgasm, anejaculation, Peyronie-like } \\
\text { disease, and penile size changes. }\end{array}$ & Strong \\
\hline $\begin{array}{l}\text { Initiate lifestyle changes and risk factor modification prior to, } \\
\text { or at the same time as, initiating ED treatments. }\end{array}$ & Strong \\
\hline Treat a curable cause of ED first, when found. & Weak \\
\hline Use PDE5Is as a first-line therapeutic option. & Strong \\
\hline $\begin{array}{l}\text { Use topical/intraurethral alprostadil as an alternative first- } \\
\text { line therapy in well-informed patients who do not wish to } \\
\text { have or are not suitable for oral vasoactive therapy. }\end{array}$ & Weak \\
\hline $\begin{array}{l}\text { Use topical/intraurethral alprostadil as an alternative first- } \\
\text { line therapy in well-informed patients who do not wish to } \\
\text { have intracavernous injections or in patients who prefer a } \\
\text { less invasive therapy. }\end{array}$ & Weak \\
\hline $\begin{array}{l}\text { Use LI-SWT in patients with mild vasculogenic ED or as an } \\
\text { alternative first-line therapy in well-informed patients who } \\
\text { do not wish to have or are not suitable for oral vasoactive } \\
\text { therapy or who desire a curable option. } \\
\text { Use LI-SWT in vasculogenic ED patients who are poor } \\
\text { responders to PDE5Is. }\end{array}$ & Weak \\
\hline $\begin{array}{l}\text { Use VEDs as a first-line therapy in well-informed patients } \\
\text { with infrequent sexual intercourse and comorbidity } \\
\text { requiring noninvasive, drug-free management of ED. }\end{array}$ & Weak \\
\hline $\begin{array}{l}\text { Use intracavernous injections as an alternative first-line } \\
\text { therapy in well-informed patients or as a second-line } \\
\text { therapy. }\end{array}$ & Strong \\
\hline $\begin{array}{l}\text { Use implantation of a penile prosthesis if other treatments } \\
\text { fail or based upon patient preference. }\end{array}$ & Strong \\
\hline $\begin{array}{l}\text { Data are inadequate to support the use of any specific } \\
\text { regimen for penile rehabilitation after radical prostatectomy. }\end{array}$ & Strong \\
\hline $\begin{array}{l}\text { Proerectile treatments should start at the earliest } \\
\text { opportunity after radical prostatectomy/pelvic surgery and } \\
\text { other curative treatments for PCa. }\end{array}$ & Weak \\
\hline \multicolumn{2}{|c|}{$\begin{array}{l}\text { CBT = cognitive and behaviour therapy; } \mathrm{ED}=\text { erectile dysfunction; LI- } \\
\text { SWT = low-intensity shockwave treatment; PCa = prostate cancer; } \\
\text { PDE5Is = phosphodiesterase type } 5 \quad \text { inhibitors; } \mathrm{RP}=\text { radical } \\
\text { prostatectomy; VED = vacuum erection device. }\end{array}$} \\
\hline
\end{tabular}

interference with these pathways may cause a wide spectrum of ejaculatory disorders (ie, PE, retarded or delayed ejaculation, anejaculation, painful ejaculation, retrograde ejaculation, anorgasmia, and haemospermia). A detailed discussion of the EAU recommendations for the entire spectrum of ejaculatory disorders can be found in the EAU guidelines [3]. Here, PE and haemospermia will be discussed in more detail.

\subsubsection{Premature ejaculation}

3.3.1.1. Definition and epidemiology of PE. The EAU guidelines have adopted the definition of PE that has been developed by the International Society for Sexual Medicine (ISSM) as the first evidence-based definition [157]. According to this definition, PE (lifelong and acquired) is a male sexual dysfunction characterised by the following: (1) ejaculation that always or nearly always occurs prior to or within about 1 min of vaginal penetration (lifelong PE) or a clinically significant and bothersome reduction in latency time, often to about $\leq 3 \mathrm{~min}$ (acquired PE); (2) the inability to delay ejaculation in all or nearly all vaginal penetrations; and (3) negative personal consequences, such as distress, bother, frustration, and/or the avoidance of sexual intimacy.

Two more PE syndromes have been proposed [158]:

1 "Variable PE" is characterised by inconsistent and irregular early ejaculations, representing a normal variation in sexual performance.

2 "Subjective PE" is characterised by subjective perception of consistent or inconsistent rapid ejaculation during intercourse, while ejaculation latency time is in the normal range or can last even longer. It should not be regarded as a symptom or manifestation of true medical pathology.

The addition of these new types may help in overcoming the limitations of each individual definition, and it may support a more flexible view of PE for patient stratification, diagnosis, and treatment [158].

The major problem in assessing the prevalence of $\mathrm{PE}$ is the lack of a universally recognised definition at the time the surveys were conducted [158]. For instance, historical data from the PE Prevalence and Attitudes (PEPA) survey of 12133 participants suggested that the prevalence of PE was $22.7 \%$ and did not vary significantly with age among men over the age of $24 \mathrm{yr}$ [159]. Two separate observational, cross-sectional surveys from different continents found the overall prevalence of the complaint of PE to be $19.8 \%$ and $25.80 \%$ [160,161]. An approximately 5\% prevalence of acquired PE and lifelong PE in general populations is consistent with epidemiological data indicating that around $5 \%$ of the population have an ejaculation latency of $<2$ min [162].

3.3.1.2. Diagnostic evaluation of PE. Diagnosis of PE is based on the patient's medical and sexual history [3]. History should classify PE as lifelong or acquired, and determine whether $\mathrm{PE}$ is situational (under specific circumstances or with a specific partner) or consistent. Specific attention should be given to the duration time of ejaculation, degree of sexual stimulus, impact on sexual activity and QoL, and drug use or abuse. It is also important to distinguish PE from ED. Many patients with ED develop secondary PE caused by the anxiety associated with difficulty in attaining and maintaining an erection [163].

Although it has been suggested as an objective diagnostic criterion and treatment outcome measure [3], the use of intravaginal ejaculatory latency time (IELT) alone is not sufficient to define $\mathrm{PE}$, as there is a significant overlap between men with and without PE [164]. Moreover, some men may experience PE in their noncoital sexual activities (eg, during masturbation, oral sex, or anal intercourse); thus, measuring IELT will not be suitable for their assessment. Moreover, perceived control over ejaculation 
has a significant direct effect on both ejaculation-related personal distress and satisfaction with sexual intercourse (each showing direct effects on interpersonal difficulty related to ejaculation) [165]. In everyday clinical practice, self-estimated IELT is sufficient [166]. Conversely, measurement of IELT with a calibrated stopwatch is mandatory in clinical trials $[3,167]$.

The need to assess PE objectively has led to the development of several questionnaires based on the use of patient-reported outcomes. Only two questionnaires can discriminate between patients who have PE and those who do not: (1) Premature Ejaculation Diagnostic Tool-a total score of $>11$ suggests a diagnosis of $\mathrm{PE}$, and a score of 9 or 10 suggests a probable diagnosis of PE [168], and (2) Arabic Index of Premature Ejaculation-a cut-off score of 30 (range of scores 7-35) discriminated PE diagnosis best [169]. Questionnaires are a significant step in simplifying the methodology of PE drug studies, although further cross-cultural validation is needed [161].

Physical examination may be a part of the initial assessment of men with PE. It may include a focused examination of the urological, endocrine, and neurological systems to identify underlying medical conditions associated with PE or other sexual dysfunctions, such as endocrinopathy, PD, urethritis, or prostatitis. Laboratory or physiological testing should be directed by specific findings from history or physical examination, and is not recommended routinely [3].

Table 9 details the EAU guideline recommendations for the diagnostic evaluation of PE.

3.3.1.3. Therapeutic management of PE. After the subtype of PE has been defined, patient's expectations should be discussed thoroughly [3]. Pharmacotherapy must be considered as the first-line treatment for patients with lifelong PE, whereas treating the underlying cause (eg, ED, prostatitis, LUTS, anxiety, hyperthyroidism, etc.) must be the initial goal for patients with acquired PE (Fig. 5) [162,170].

Dapoxetine (30 and $60 \mathrm{mg}$ ) is the first on-demand oral pharmacological agent approved for lifelong and acquired PE in many countries, except for the USA [171-173]. Dapoxetine has shown a similar efficacy profile in men with lifelong and acquired PE $[3,171,172,174,175]$. Treatmentrelated side effects were dose dependent and included nausea, diarrhoea, headache, and dizziness $[3,176]$. Moreover, the eutectic metered-dose aerosol spray of lidocaine $(150 \mathrm{mg} / \mathrm{ml})$ and prilocaine $(50 \mathrm{mg} / \mathrm{ml})$ combination is the first topical formula to be officially approved for the ondemand treatment of lifelong PE by the EMA in the European Union [177]. Compared with topical creams, the metered-dose spray delivery system has been proved to deposit the drug in a dose-controlled, concentrated film covering the glans penis, maximising neural blockage and minimising the onset of numbness [178], without absorption through the penile shaft skin [179]. Based on available data, the recommended dose of lidocaine/prilocaine spray is one dose (namely, three sprays) to be applied on the glans penis at least 5 min before sexual intercourse [180]. A low incidence of local treatment-emergent adverse events
Table 9 - Recommendations for the diagnostic evaluation of premature ejaculation

\begin{tabular}{lc}
\hline Recommendations & $\begin{array}{c}\text { Strength } \\
\text { rating }\end{array}$ \\
\hline $\begin{array}{l}\text { Perform the diagnosis and classification of PE based on } \\
\text { medical and sexual history, which should include assessment } \\
\text { of IELT (self-estimated), perceived control, distress, and } \\
\text { interpersonal difficulty due to ejaculatory dysfunction. }\end{array}$ & Strong \\
$\begin{array}{l}\text { Use of stopwatch-measured IELT is not compulsory in clinical } \\
\text { practice. }\end{array}$ & Weak \\
$\begin{array}{l}\text { Use patient-reported outcomes in daily clinical practice. } \\
\begin{array}{l}\text { Include physical examination in the initial assessment of PE } \\
\text { to identify anatomical abnormalities that may be associated }\end{array}\end{array}$ & Strong \\
$\begin{array}{l}\text { with PE or other sexual dysfunctions, particularly ED. } \\
\begin{array}{l}\text { Do not perform routine laboratory or neurophysiological } \\
\text { tests. They should only be directed by specific findings from } \\
\text { history or physical examination. }\end{array}\end{array}$ & Strong \\
\hline $\begin{array}{l}\text { ED }=\text { erectile dysfunction; IELT = intravaginal ejaculatory latency time; } \\
\text { PE }=\text { premature ejaculation. }\end{array}$ \\
\hline
\end{tabular}

(TEAEs) in both patients and partners has been reported, including genital hypoesthesia (4.5\% and $1.0 \%$ in partners of males and females, respectively), ED (4.4\%), and vulvovaginal burning sensation (3.9\%), but is unlikely to be associated with systemic TEAEs [181].

All other medications used in PE are off-label indications [172]. Daily or on-demand use of selective serotonin reuptake inhibitors (SSRIs) and clomipramine, and ondemand topical anaesthetic agents have consistently shown efficacy in PE [172]. Of all, several systematic reviews and meta-analyses of drug treatment studies showed that, despite methodological problems in most studies, daily SSRIs are significantly effective for PE [3,176,182]. Paroxetine was found to be superior to fluoxetine, clomipramine, and sertraline [3,183-186]. Likewise, tramadol, a mild opioid receptor agonist that also promotes reuptake inhibition of serotonin and noradrenaline, has been demonstrated to be effective as an off-label on-demand oral therapy in men with a history of lifelong PE $[3,187,188]$. Side effects were reported at doses used for analgesic purposes (up to $400 \mathrm{mg}$ daily) and include constipation, sedation, and dry mouth. The efficacy and safety of tramadol have been confirmed in systematic reviews and meta-analyses [182,189-191]. As a whole, long-term outcomes of pharmacological treatments are unknown $[3,176,182,192]$. Figure 5 provides a treatment algorithm for PE management.

Overall, PDE5Is were found to be significantly more effective than placebo in the treatment of patients with PE and without ED [192]. Moreover, some meta-analyses demonstrated that the combined use of SSRIs and PDE5Is may be more effective than SSRI or PDE5I monotherapy $[3,193,194]$.

In lifelong PE, behavioural techniques are not recommended alone, and pharmacotherapy must be considered as the basis of treatment [162]. Accordingly, psychosexual interventions, irrespective of whether these are behavioural, cognitive, or focused on the couple, are aimed at teaching techniques to control/delay ejaculation, gaining confidence in sexual performance, reducing anxiety, and promoting communication and problem solving within the 


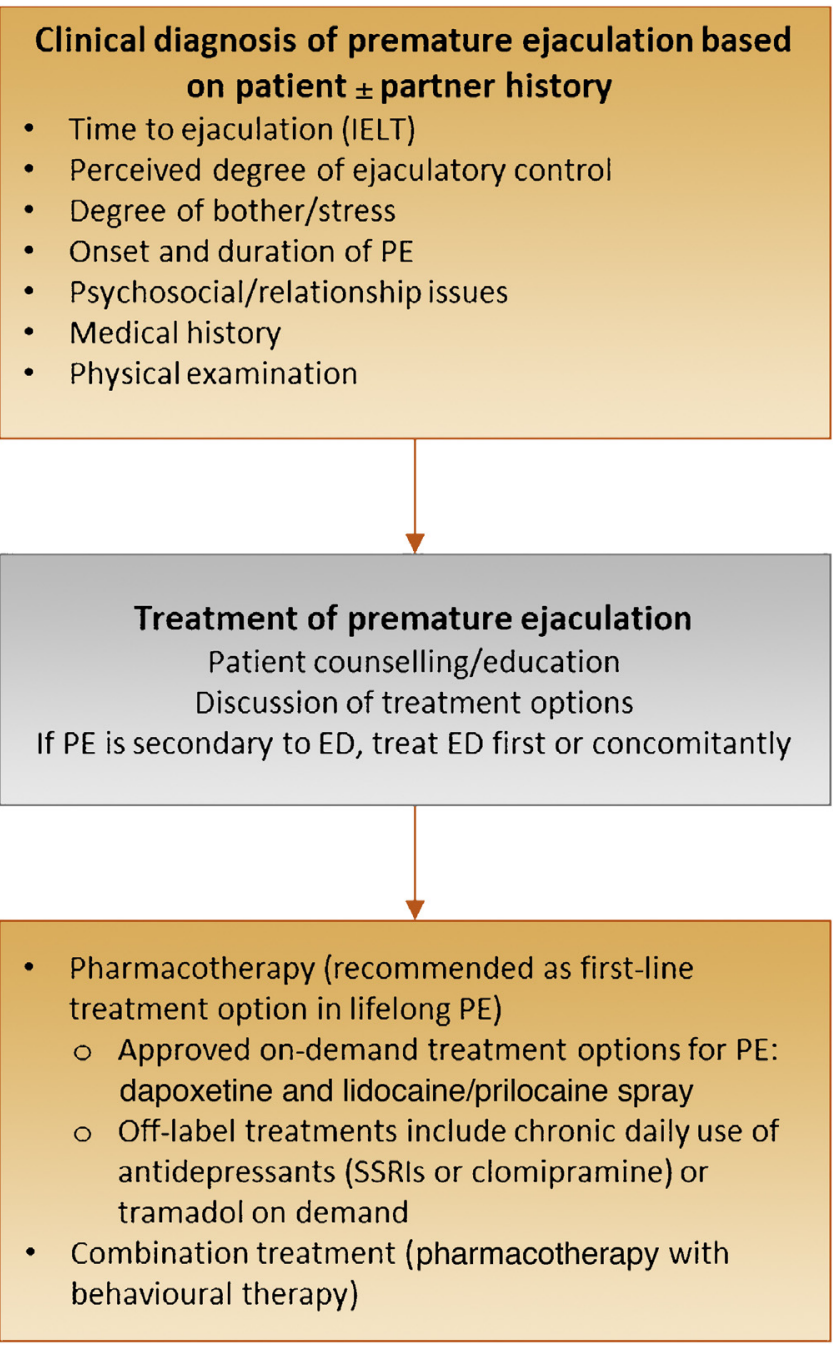

Fig. 5 - Management of premature ejaculation. ED = erectile dysfunction; IELT = intravaginal ejaculatory latency time; PE = premature ejaculation; SSRI = selective serotonin receptor inhibitor. Adapted from Lue et al [170].

couple [195]. It is worth noting, however, that psychosexual interventions alone regarding PE lack empirical support. Yet, recent evidence suggested that start-stop exercises, combined with psychoeducation and mindfulness techniques, improved PE symptoms as well as PE-associated distress, anxiety, and depression [196,197]. Behavioural therapy may be most effective when used to "add value" to medical interventions (eg, dapoxetin) [198]. Validated assessment instruments need to be used as an end-point. Longer follow-up periods are necessary to confirm these findings [3].

Table 10 lists the EAU guideline recommendations for the treatment of PE.

\subsubsection{Haemospermia}

3.3.2.1. Definition, classification, and epidemiology of haemospermia. Haemospermia is defined as the appearance of blood in the ejaculate. Although it is often regarded as a symptom of minor significance, blood in the ejaculate causes great
Table 10 - Recommendations for the treatment of premature ejaculation

\begin{tabular}{|c|c|}
\hline Recommendations & $\begin{array}{l}\text { Strength } \\
\text { rating }\end{array}$ \\
\hline $\begin{array}{l}\text { Treat ED, other sexual dysfunction, or genitourinary infection } \\
\text { (eg, prostatitis) first. }\end{array}$ & Strong \\
\hline $\begin{array}{l}\text { Use either dapoxetine or the lidocaine/prilocaine spray as } \\
\text { first-line treatments for lifelong PE. }\end{array}$ & Strong \\
\hline $\begin{array}{l}\text { Use off-label topical anaesthetic agents as a viable } \\
\text { alternative to oral treatment with SSRIs. }\end{array}$ & Strong \\
\hline Use tramadol on demand as a weak alternative to SSRIs. & Weak \\
\hline $\begin{array}{l}\text { Use PDE5Is alone or in combination with other therapies in } \\
\text { patients with PE (without ED). }\end{array}$ & Strong \\
\hline $\begin{array}{l}\text { Use psychological/behavioural therapies in combination } \\
\text { with pharmacological treatment in the management of } \\
\text { acquired PE. }\end{array}$ & Weak \\
\hline $\begin{array}{l}\mathrm{ED}=\text { erectile dysfunction; } \quad \mathrm{PE}=\text { premature } \\
\text { PDE5Is = phosphodiesterase type } 5 \text { inhibitors; SSRIs = select } \\
\text { reuptake inhibitors. }\end{array}$ & $\begin{array}{l}\text { jaculation; } \\
\text { e serotonin }\end{array}$ \\
\hline
\end{tabular}

anxiety in many men and may be indicative of underlying pathology [199]. The exact incidence and prevalence of haemospermia are difficult to elucidate due to a number of factors, including its covert presentation, usually selflimiting nature, and patient embarrassment. The symptom represents approximately $1-1.5 \%$ of all urological referrals and occurs in all age groups, with a mean age of $37 \mathrm{yr}$ $[199,200]$. Several reasons of haemospermia have been acknowledged and can be classified into the following subcategories: idiopathic, congenital malformations, inflammation/infections, obstruction, malignancies (eg, genitourinary cancers: prostate and testis), vascular abnormalities, iatrogenic/trauma, and systemic causes (Supplementary Table 5) [201,202]. The risk of malignancy in patients presenting with haemospermia is approximately $3.5 \%(0-13.1 \%)[209,210]$.

3.3.2.2. Investigations for haemospermia. As with other clinical conditions, a systematic clinical history and assessment to help identify the reason of haemospermia is undertaken. Although the differential diagnosis is extensive, most cases are caused by infections or other inflammatory processes $[199,202]$. A sexual history should be taken to identify those whose haemospermia may be as a consequence of a sexually transmitted disease. Recent foreign travel to areas affected by schistosomiasis or tuberculosis should also be considered. A urinalysis should be performed along with sending the urine for culture and sensitivities as well as microscopy. If tuberculosis or schistosomiasis is the suspected cause, the semen or prostatic secretions should be sent for analysis. A full sexually transmitted disease screen should include assessment for Chlamydia, Ureaplasma, and herpes simplex. Using this strategy, it may be possible to find an infectious agent among patients who would have been labelled to have idiopathic haemospermia [203]. The possibility of coexisting systemic disease such as hypertension, liver disease, and coagulopathies should be investigated along with systemic features of malignancy. Examination of the patient should also include measure- 
Table 11 - Recommendations for the management of recurrent haemospermia

\begin{tabular}{lc}
\hline Recommendations & $\begin{array}{c}\text { Strength } \\
\text { rating }\end{array}$ \\
\hline $\begin{array}{l}\text { Perform a full medical and sexual history with detailed } \\
\text { physical examination. }\end{array}$ & Strong \\
$\begin{array}{l}\text { Men aged } \geq 40 \text { yr with persistent haemospermia should be } \\
\text { screened for PCa. }\end{array}$ & Weak \\
$\begin{array}{l}\text { Consider noninvasive imaging modalities (TRUS and MRI) in } \\
\text { men aged } \geq 40 \text { yr or men of any age with persistent or } \\
\text { refractory haemospermia. }\end{array}$ & Weak \\
$\begin{array}{l}\text { Consider invasive methods such as cystoscopy and } \\
\text { vesiculoscopy when noninvasive methods are inconclusive. }\end{array}$ & Weak \\
\hline $\begin{array}{l}\text { MRI = magnetic resonance imaging; PCa = prostate } \\
\text { TRUS = transrectal ultrasound. }\end{array}$ & cancer; \\
\hline
\end{tabular}

ment of the blood pressure, as there have been several case reports suggesting an association between uncontrolled hypertension and haemospermia [204,205]. Blood work including a full blood count, liver function tests, and a clotting screen should be taken to identify systemic diseases. A serum PSA measurement should be performed in men over the age of $40 \mathrm{yr}$ who have been counselled appropriately. DRE should also be performed and the meatus re-examined after DRE for the presence of bloody discharge [206].

TRUS and MRI are increasingly used as a definitive means to investigate haemospermia (Table 11) [211-213]. The use of cystoscopy has been included in the majority of suggested investigation protocols in patients with highrisk features (patients who are refractory to conservative treatments and those with persistent haemospermia) [200]. With the advancement of optics, it has been made possible to create ureteroscopes of diameters small enough to allow insertion into the ejaculatory duct and seminal vesicles (seminal vesiculoscopy) [3].

3.3.2.3. Disease management. The primary goal of the treatment is to exclude malignant conditions such as prostate and bladder cancer, and treat any other underlying cause. Conservative management is generally the primary treatment option when the patients are younger than $40 \mathrm{yr}$ of

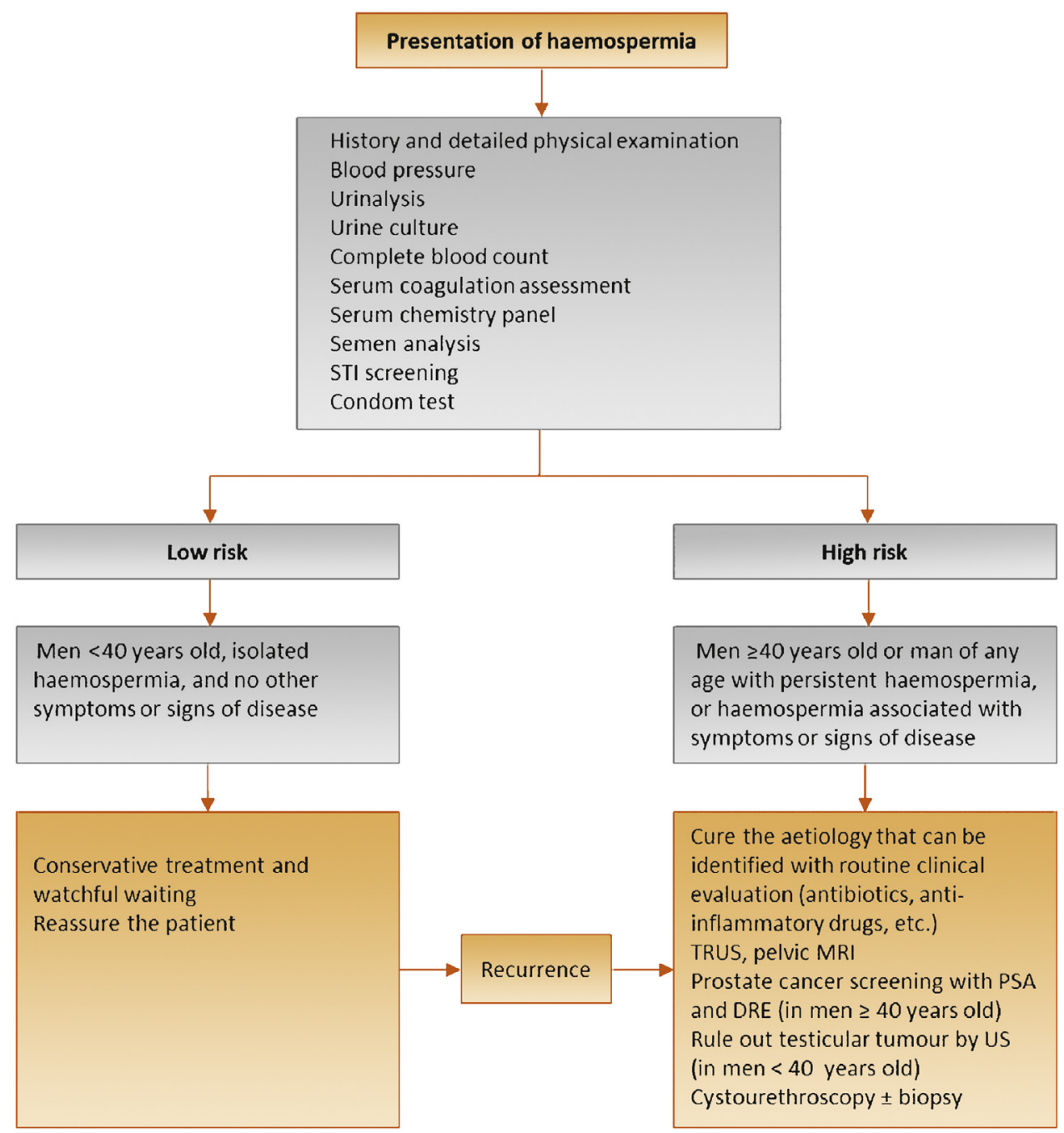

Fig. 6 - Management algorithm for haemospermia. DRE = digital rectal examination; $M R I$ = magnetic resonance imaging; PSA = prostate-specific antigen; STI = sexually transmitted infections; TRUS = transrectal ultrasonography; US = ultrasonography. 
age and have a single episode of haemospermia [199]. Patients with recurrent haemospermia and those who are middle aged warrant a more aggressive intervention. Appropriate antibiotic therapy should be given to patients who have urogenital infections or sexually transmitted infections. Urethral or prostate varices or angiodysplastic vessels can be fulgurated, whereas cysts of either the seminal vesicles or the prostatic urethra can be aspirated transrectally [199]. Ejaculatory duct obstruction is managed by a transurethral incision at the duct opening [207]. Systemic conditions should be treated appropriately [208]. Based on the literature, a management algorithm is proposed (Fig. 6).

Table 11 lists the EAU guideline recommendations for the management of recurrent haemospermia.

\section{Conclusions}

The present text represents a summary of the 2021 EAU guidelines on sexual and reproductive health, dealing with male sexual dysfunction. A summary of recommendations is presented for the following disorders: male hypogonadism, ED, PE, and recurrent haemospermia. For more detailed information and a full list of references, refer to the full-text version available at the EAU website (https://uroweb.org/ guideline/sexual-and-reproductive-health/).

Author contributions: Andrea Salonia had full access to all the data in the study and takes responsibility for the integrity of the data and the accuracy of the data analysis.

Study concept and design: Salonia, Bettocchi, Boeri, Capogrosso, Carvalho, Cilesiz, Cocci, Corona, Dimitropoulos, Gül, Hatzichristodoulou, Jones, Kadioglu, Martínez Salamanca, Milenkovic, Modgil, Russo, Serefoglu, Tharakan, Verze, Minhas.

Acquisition of data: Salonia, Bettocchi, Boeri, Capogrosso, Carvalho, Cilesiz, Cocci, Corona, Dimitropoulos, Gül, Hatzichristodoulou, Jones, Kadioglu, Martínez Salamanca, Milenkovic, Modgil, Russo, Serefoglu, Tharakan, Verze, Minhas.

Analysis and interpretation of data: Salonia, Bettocchi, Boeri, Capogrosso, Carvalho, Cilesiz, Cocci, Corona, Dimitropoulos, Gül, Hatzichristodoulou, Jones, Kadioglu, Martínez Salamanca, Milenkovic, Modgil, Russo, Serefoglu, Tharakan, Verze, Minhas.

Drafting of the manuscript: Salonia, Bettocchi, Boeri, Capogrosso, Carvalho, Cilesiz, Cocci, Corona, Dimitropoulos, Gül, Hatzichristodoulou, Jones, Kadioglu, Martínez Salamanca, Milenkovic, Modgil, Russo, Serefoglu, Tharakan, Verze, Minhas.

Critical revision of the manuscript for important intellectual content: Salonia, Bettocchi, Boeri, Capogrosso, Carvalho, Cilesiz, Cocci, Corona, Dimitropoulos, Gül, Hatzichristodoulou, Jones, Kadioglu, Martínez Salamanca, Milenkovic, Modgil, Russo, Serefoglu, Tharakan, Verze, Minhas.

Statistical analysis: Salonia, Bettocchi, Boeri, Capogrosso, Carvalho, Cilesiz, Cocci, Corona, Dimitropoulos, Gül, Hatzichristodoulou, Jones, Kadioglu, Martínez Salamanca, Milenkovic, Modgil, Russo, Serefoglu, Tharakan, Verze, Minhas.

Obtaining funding: European Association of Urology.

Administrative, technical, or material support: Salonia, Minhas.

Supervision: Salonia, Minhas.

Other: None.
Financial disclosures: Andrea Salonia certifies that all conflicts of interest, including specific financial interests and relationships and affiliations relevant to the subject matter or materials discussed in the manuscript (eg, employment/affiliation, grants or funding, consultancies, honoraria, stock ownership or options, expert testimony, royalties, or patents filed, received, or pending), are the following: None.

Funding/Support and role of the sponsor: This work was supported by European Association of Urology.

Acknowledgements: The authors acknowledge Julie Darraugh and Karin Plass, for their constant support from the EAU Guidelines Office, and Edoardo Pozzi, MD, for the great support during the preparation of the manuscript.

\section{Appendix A. Supplementary data}

Supplementary material related to this article can be found, in the online version, at doi:https://doi.org/10.1016/j. eururo.2021.06.007.

\section{References}

[1] Hatzimouratidis K, Amar E, Eardley I, et al. Guidelines on male sexual dysfunction: erectile dysfunction and premature ejaculation. Eur Urol 2010;57:804-14.

[2] Hatzimouratidis K, Eardley I, Giuliano F, et al. EAU guidelines on penile curvature. Eur Urol 2012;62:543-52.

[3] Salonia A, Bettocchi C, Carvalho J, et al. EAU guidelines on sexual and reproductive health. https://uroweb.org/wp-content/uploads/ EAU-Guidelines-on-Sexual-and-Reproductive-Health-2021.pdf.

[4] Guyatt GH, Oxman AD, Kunz R, et al. Going from evidence to recommendations. BMJ 2008;336:1049-51.

[5] Salonia A, Rastrelli G, Hackett G, et al. Paediatric and adult-onset male hypogonadism. Nat Rev Dis Primer 2019;5:38.

[6] Khera M, Adaikan G, Buvat J, et al. Diagnosis and treatment of testosterone deficiency: recommendations from the Fourth International Consultation for Sexual Medicine (ICSM 2015). J Sex Med 2016;13:1787-804.

[7] Wu FCW, Tajar A, Beynon JM, et al. Identification of late-onset hypogonadism in middle-aged and elderly men. $\mathrm{N}$ Engl J Med 2010;363:123-35.

[8] Zarotsky V, Huang M-Y, Carman W, et al. Systematic literature review of the risk factors, comorbidities, and consequences of hypogonadism in men. Andrology 2014;2:819-34.

[9] Araujo AB, Dixon JM, Suarez EA, Murad MH, Guey LT, Wittert GA. Clinical review: endogenous testosterone and mortality in men: a systematic review and meta-analysis. J Clin Endocrinol Metab 2011;96:3007-19.

[10] Wu FCW, Tajar A, Pye SR, et al. Hypothalamic-pituitary-testicular axis disruptions in older men are differentially linked to age and modifiable risk factors: the European Male Aging Study. J Clin Endocrinol Metab 2008;93:2737-45.

[11] Kapoor D, Aldred H, Clark S, Channer KS, Jones TH. Clinical and biochemical assessment of hypogonadism in men with type 2 diabetes: correlations with bioavailable testosterone and visceral adiposity. Diabetes Care 2007;30:911-7.

[12] Maseroli E, Corona G, Rastrelli G, et al. Prevalence of endocrine and metabolic disorders in subjects with erectile dysfunction: a comparative study. J Sex Med 2015;12:956-65.

[13] Kanakis GA, Nieschlag E. Klinefelter syndrome: more than hypogonadism. Metabolism 2018;86:135-44. 
[14] Santi D, Corona G. Primary and secondary hypogonadism. In: Simoni M, Huhtaniemi IT, editors. Endocrinology of the testis and male reproduction. Cham, Switzerland: Springer International Publishing; 2017. p. 687-747.

[15] Tajar A, Forti G, O'Neill TW, et al. Characteristics of secondary, primary, and compensated hypogonadism in aging men: evidence from the European Male Ageing Study. J Clin Endocrinol Metab 2010;95:1810-8.

[16] Corona G, Rastrelli G, Dicuio M, et al. Subclinical male hypogonadism. Minerva Endocrinol 2020. http://dx.doi.org/10.23736/ S0391-1977.20.03208-3, Epub ahead of print. PMID: 32969626. Sep 24.

[17] Grossmann M, Matsumoto AM. A perspective on middle-aged and older men with functional hypogonadism: focus on holistic management. J Clin Endocrinol Metab 2017;102:1067-75.

[18] Corona G, Goulis DG, Huhtaniemi I, et al. European Academy of Andrology (EAA) guidelines on investigation, treatment and monitoring of functional hypogonadism in males: endorsing organization: European Society of Endocrinology. Andrology 2020;8:970-87.

[19] Travison TG, Vesper HW, Orwoll E, et al. Harmonized reference ranges for circulating testosterone levels in men of four cohort studies in the United States and Europe. J Clin Endocrinol Metab 2017; 102:1161-73.

[20] Gagliano-Jucá T, Li Z, Pencina KM, et al. Oral glucose load and mixed meal feeding lowers testosterone levels in healthy eugonadal men. Endocrine 2019;63:149-56.

[21] Huhtaniemi IT, Tajar A, Lee DM, et al. Comparison of serum testosterone and estradiol measurements in 3174 European men using platform immunoassay and mass spectrometry; relevance for the diagnostics in aging men. Eur J Endocrinol 2012;166:983-91.

[22] Vermeulen A, Verdonck L, Kaufman JM. A critical evaluation of simple methods for the estimation of free testosterone in serum. J Clin Endocrinol Metab 1999;84:3666-72.

[23] Corona G, Rastrelli G, Morgentaler A, Sforza A, Mannucci E, Maggi M. Meta-analysis of results of testosterone therapy on sexual function based on International Index of Erectile Function scores. Eur Urol 2017;72:1000-11.

[24] Isidori AM, Buvat J, Corona G, et al. A critical analysis of the role of testosterone in erectile function: from pathophysiology to treatment-a systematic review. Eur Urol 2014;65:99-112.

[25] Boeri L, Capogrosso P, Ventimiglia E, et al. Does calculated free testosterone overcome total testosterone in protecting from sexual symptom impairment? Findings of a cross-sectional study. J Sex Med 2017;14:1549-57.

[26] Isidori AM, Balercia G, Calogero AE, et al. Outcomes of androgen replacement therapy in adult male hypogonadism: recommendations from the Italian Society of Endocrinology. J Endocrinol Invest 2015;38:103-12.

[27] Bhasin S, Brito JP, Cunningham GR, et al. Testosterone therapy in men with hypogonadism: an Endocrine Society clinical practice guideline. J Clin Endocrinol Metab 2018;103:1715-44.

[28] Molitch ME. Diagnosis and treatment of pituitary adenomas: a review. JAMA 2017;317:516-24.

[29] Corona G, Mannucci E, Petrone L, et al. ANDROTEST: a structured interview for the screening of hypogonadism in patients with sexual dysfunction. J Sex Med 2006;3:706-15.

[30] Millar AC, Lau ANC, Tomlinson G, et al. Predicting low testosterone in aging men: a systematic review. CMAJ Can Med Assoc J 2016;188:E321-30.

[31] Corona G, Rastrelli G, Monami M, et al. Body weight loss reverts obesity-associated hypogonadotropic hypogonadism: a systematic review and meta-analysis. Eur J Endocrinol 2013;168:829-43.
[32] van Hulsteijn LT, Pasquali R, Casanueva F, et al. Prevalence of endocrine disorders in obese patients: systematic review and meta-analysis. Eur J Endocrinol 2020;182:11-21.

[33] Rastrelli G, Vignozzi L, Corona G, Maggi M. Testosterone and benign prostatic hyperplasia. Sex Med Rev 2019;7:259-71.

[34] Shabsigh R, Crawford ED, Nehra A, Slawin KM. Testosterone therapy in hypogonadal men and potential prostate cancer risk: a systematic review. Int J Impot Res 2009;21:9-23.

[35] Morelli A, Corona G, Filippi S, et al. Which patients with sexual dysfunction are suitable for testosterone replacement therapy? J Endocrinol Invest 2007;30:880-8.

[36] Colpi GM, Francavilla S, Haidl G, et al. European Academy of Andrology guideline management of oligo-astheno-teratozoospermia. Andrology 2018;6:513-24.

[37] Huo S, Scialli AR, McGarvey S, et al. Treatment of men for "low testosterone": a systematic review. PLoS One 2016;11:e0162480.

[38] Rastrelli G, Guaraldi F, Reismann Y, et al. Testosterone replacement therapy for sexual symptoms. Sex Med Rev 2019;7:464-75.

[39] Elliott J, Kelly SE, Millar AC, et al. Testosterone therapy in hypogonadal men: a systematic review and network meta-analysis. BMJ Open 2017;7:e015284.

[40] Corona G, Vignozzi L, Sforza A, Mannucci E, Maggi M. Obesity and late-onset hypogonadism. Mol Cell Endocrinol 2015;418(Pt 2):120-33.

[41] Corona G, Giagulli VA, Maseroli E, et al. Testosterone supplementation and body composition: results from a meta-analysis of observational studies. J Endocrinol Invest 2016;39:967-81.

[42] Rosen RC, Wu F, Behre HM, et al. Quality of life and sexual function benefits of long-term testosterone treatment: longitudinal results from the Registry of Hypogonadism in Men (RHYME). J Sex Med 2017;14:1104-15.

[43] Groti K, Žuran I, Antonič B, Foršnarič L, Pfeifer M. The impact of testosterone replacement therapy on glycemic control, vascular function, and components of the metabolic syndrome in obese hypogonadal men with type 2 diabetes. Aging Male 2018;21:158-69.

[44] Wittert G, Bracken K, Robledo KP, et al. Testosterone treatment to prevent or revert type 2 diabetes in men enrolled in a lifestyle programme (T4DM): a randomised, double-blind, placebo-controlled, 2-year, phase 3b trial. Lancet Diabetes Endocrinol 2021;9:32-45.

[45] Haider KS, Haider A, Saad F, et al. Remission of type 2 diabetes following long-term treatment with injectable testosterone undecanoate in patients with hypogonadism and type 2 diabetes: 11year data from a real-world registry study. Diabetes Obes Metab 2020;22:2055-68.

[46] Smith JB, Rosen J, Colbert A. Low serum testosterone in outpatient psychiatry clinics: addressing challenges to the screening and treatment of hypogonadism. Sex Med Rev 2018;6:69-76.

[47] Walther A, Breidenstein J, Miller R. Association of testosterone treatment with alleviation of depressive symptoms in men: a systematic review and meta-analysis. JAMA Psychiatry 2019;76: 31-40.

[48] Nian Y, Ding M, Hu S, et al. Testosterone replacement therapy improves health-related quality of life for patients with late-onset hypogonadism: a meta-analysis of randomized controlled trials. Andrologia 2017;49:e12630.

[49] Corona G, Guaraldi F, Rastrelli G, Sforza A, Maggi M. Testosterone deficiency and risk of cognitive disorders in aging males. World J Mens Health 2021;39:9-18.

[50] Snyder PJ, Bhasin S, Cunningham GR, et al. Lessons from the testosterone trials. Endocr Rev 2018;39:369-86.

[51] Rochira V, Antonio L, Vanderschueren D. EAA clinical guideline on management of bone health in the andrological outpatient clinic. Andrology 2018;6:272-85. 
[52] Isidori AM, Giannetta E, Greco EA, et al. Effects of testosterone on body composition, bone metabolism and serum lipid profile in middle-aged men: a meta-analysis. Clin Endocrinol (Oxf) 2005;63:280-93.

[53] Tracz MJ, Sideras K, Bolona ER, et al. Testosterone use in men and its effects on bone health: a systematic review and meta-analysis of randomized placebo-controlled trials. Centre for Reviews and Dissemination (UK); 2006.

[54] Steeves JA, Fitzhugh EC, Bradwin G, McGlynn KA, Platz EA, Joshu CE. Cross-sectional association between physical activity and serum testosterone levels in US men: results from NHANES 19992004. Andrology 2016;4:465-72.

[55] Corona G, Maggi M. Deciding which testosterone therapy to prescribe. J Sex Med 2018;15:619-21.

[56] Kohn TP, Mata DA, Ramasamy R, Lipshultz LI. Effects of testosterone replacement therapy on lower urinary tract symptoms: a systematic review and meta-analysis. Eur Urol 2016;69:1083-90.

[57] Kathrins M, Doersch K, Nimeh T, Canto A, Niederberger C, Seftel A. The relationship between testosterone-replacement therapy and lower urinary tract symptoms: a systematic review. Urology 2016;88:22-32.

[58] Lopez DS, Advani S, Tsilidis KK, Wang R, Canfield S. Endogenous and exogenous testosterone and prostate cancer: decreased-, increased- or null-risk? Transl Androl Urol 2017;6:566-79.

[59] Watts EL, Appleby PN, Perez-Cornago A, et al. Low free testosterone and prostate cancer risk: a collaborative analysis of 20 prospective studies. Eur Urol 2018;74:585-94.

[60] Haider A, Zitzmann M, Doros G, Isbarn H, Hammerer P, Yassin A. Incidence of prostate cancer in hypogonadal men receiving testosterone therapy: observations from 5-year median followup of 3 registries. J Urol 2015;193:80-6.

[61] Teeling F, Raison N, Shabbir M, Yap T, Dasgupta P, Ahmed K. Testosterone therapy for high-risk prostate cancer survivors: a systematic review and meta-analysis. Urology 2019;126:16-23.

[62] Corona G, Rastrelli G, Di Pasquale G, Sforza A, Mannucci E, Maggi M. Endogenous testosterone levels and cardiovascular risk: metaanalysis of observational studies. J Sex Med 2018;15:1260-71.

[63] European Medicines Agency. No consistent evidence of an increased risk heart problems with testosterone medicines. In: https://www.ema.europa.eu/en/news/no-consistent-evidenceincreased-risk-heart-problems-testosterone-medicines2018

[64] Alexander GC, Iyer G, Lucas E, Lin D, Singh S. Cardiovascular risks of exogenous testosterone use among men: a systematic review and meta-analysis. Am J Med 2017;130:293-305.

[65] Corona G, Maseroli E, Rastrelli G, et al. Cardiovascular risk associated with testosterone-boosting medications: a systematic review and meta-analysis. Expert Opin Drug Saf 2014;13:1327-51.

[66] Corona G, Rastrelli G, Pasquale GD, Sforza A, Mannucci E, Maggi M. Testosterone and cardiovascular risk: meta-analysis of interventional studies. J Sex Med 2018;15:820-38.

[67] U.S. FDA. Bone, Reproductive and Urologic Drugs Advisory Committee (formerly Reproductive Health Drugs Advisory Committee). In: https://www.fda.gov/advisory-committees/ human-drug-advisory-committees/bone-reproductive-andurologic-drugs-advisory-committee-formerly-reproductivehealth-drugs-advisory 2020

[68] Calof OM, Singh AB, Lee ML, et al. Adverse events associated with testosterone replacement in middle-aged and older men: a metaanalysis of randomized, placebo-controlled trials. J Gerontol A Biol Sci Med Sci 2005;60:1451-7.

[69] Fernandez-Balsells MM, Murad MH, Lane M, et al. Adverse effects of testosterone therapy in adult men: a systematic review and meta-analysis. UK: Centre for Reviews and Dissemination; 2010.
[70] Puddu PE, Lanti M, Menotti A, et al. Red blood cell count in shortterm prediction of cardiovascular disease incidence in the Gubbio population study. Acta Cardiol 2002;57:177-85.

[71] NIH Consensus Conference. Impotence. NIH Consensus Development Panel on impotence. JAMA 1993;270:83-90.

[72] Eardley I. The incidence, prevalence, and natural history of erectile dysfunction. Sex Med Rev 2013;1:3-16.

[73] Gandaglia G, Briganti A, Jackson G, et al. A systematic review of the association between erectile dysfunction and cardiovascular disease. Eur Urol 2014;65:968-78.

[74] Besiroglu H, Otunctemur A, Ozbek E. The relationship between metabolic syndrome, its components, and erectile dysfunction: a systematic review and a meta-analysis of observational studies. J Sex Med 2015;12:1309-18.

[75] Pozzi E, Capogrosso P, Boeri L, et al. Longitudinal risk of developing cardiovascular diseases in patients with erectile dysfunctionwhich patients deserve more attention? J Sex Med 2020;17: 1489-94.

[76] Pizzol D, Smith L, Fontana L, et al. Associations between body mass index, waist circumference and erectile dysfunction: a systematic review and META-analysis. Rev Endocr Metab Disord 2020;21: 657-66.

[77] Alberti L, Torlasco C, Lauretta L, et al. Erectile dysfunction in heart failure patients: a critical reappraisal. Andrology 2013;1:177-91.

[78] Carani C, Isidori AM, Granata A, et al. Multicenter study on the prevalence of sexual symptoms in male hypo- and hyperthyroid patients. J Clin Endocrinol Metab 2005;90:6472-9.

[79] Corona G, Wu FCW, Forti G, et al. Thyroid hormones and male sexual function. Int J Androl 2012;35:668-79.

[80] Corona G, Isidori AM, Aversa A, Burnett AL, Maggi M. Endocrinologic control of men's sexual desire and arousal/erection. J Sex Med 2016;13:317-37.

[81] Corona G, Mannucci E, Fisher AD, et al. Effect of hyperprolactinemia in male patients consulting for sexual dysfunction. J Sex Med 2007;4:1485-93

[82] Yafi FA, Jenkins L, Albersen M, et al. Erectile dysfunction. Nat Rev Dis Primer 2016;2:16003.

[83] Duran MB, Yildirim O, Kizilkan Y, et al. Variations in the number of patients presenting with andrological problems during the COVID19 pandemic and the possible reasons for these variations: a multi-center study. Sex Med 2021;9:100292.

[84] Sansone A, Mollaioli D, Ciocca G, et al. Addressing male sexual and reproductive health in the wake of COVID-19 outbreak. J Endocrinol Invest 2021;44:223-31.

[85] Gupta BP, Murad MH, Clifton MM, Prokop L, Nehra A, Kopecky SL. The effect of lifestyle modification and cardiovascular risk factor reduction on erectile dysfunction: a systematic review and metaanalysis. Arch Intern Med 2011;171:1797-803.

[86] Allen MS, Walter EE. Health-related lifestyle factors and sexual dysfunction: a meta-analysis of population-based research. J Sex Med 2018;15:458-75

[87] Cui Y, Zong H, Yan H, Zhang Y. The effect of statins on erectile dysfunction: a systematic review and meta-analysis. J Sex Med 2014;11:1367-75.

[88] Rosen R, Altwein J, Boyle P, et al. Lower urinary tract symptoms and male sexual dysfunction: the multinational survey of the aging male (MSAM-7). Eur Urol 2003;44:637-49.

[89] Seftel AD, de la Rosette J, Birt J, Porter V, Zarotsky V, Viktrup L. Coexisting lower urinary tract symptoms and erectile dysfunction: a systematic review of epidemiological data. Int J Clin Pract 2013;67:32-45.

[90] Verze P, Califano G, Sokolakis I, et al. The impact of surgery for lower urinary tract symptoms/benign prostatic enlargement on 
both erectile and ejaculatory function: a systematic review. Int J Impot Res 2019;31:319-27.

[91] Li Z, Chen P, Wang J, et al. The impact of surgical treatments for lower urinary tract symptoms/benign prostatic hyperplasia on male erectile function: a systematic review and network metaanalysis. Medicine (Baltimore) 2016;95:e3862.

[92] Chung S-D, Keller J, Lin H-C. A nationwide population-based study on bladder pain syndrome/interstitial cystitis and ED.. Int J Impot Res 2013;25:224-8.

[93] Chen X, Zhou Z, Qiu X, Wang B, Dai J. The effect of chronic prostatitis/chronic pelvic pain syndrome (CP/CPPS) on erectile function: a systematic review and meta-analysis. PLoS One 2015;10:e0141447.

[94] Murray KS, Bailey J, Zuk K, Lopez-Corona E, Thrasher JB. A prospective study of erectile function after transrectal ultrasonography-guided prostate biopsy. BJU Int 2015;116:190-5.

[95] Feng C, Xu Y-M, Barbagli G, et al. The relationship between erectile dysfunction and open urethroplasty: a systematic review and meta-analysis. J Sex Med 2013;10:2060-8.

[96] Emanu JC, Avildsen IK, Nelson CJ. Erectile dysfunction after radical prostatectomy: prevalence, medical treatments, and psychosocial interventions. Curr Opin Support Palliat Care 2016;10:102-7.

[97] Salonia A, Adaikan G, Buvat J, et al. Sexual rehabilitation after treatment for prostate cancer-part 1: recommendations from the Fourth International Consultation for Sexual Medicine (ICSM 2015). J Sex Med 2017;14:285-96.

[98] Modh RA, Mulhall JP, Gilbert SM. Sexual dysfunction after cystectomy and urinary diversion. Nat Rev Urol 2014;11:445-53.

[99] Celentano V, Fabbrocile G, Luglio G, Antonelli G, Tarquini R, Bucci L. Prospective study of sexual dysfunction in men with rectal cancer: feasibility and results of nerve sparing surgery. Int J Colorectal Dis 2010;25:1441-5.

[100] Walz J, Epstein JI, Ganzer R, et al. A critical analysis of the current knowledge of surgical anatomy of the prostate related to optimisation of cancer control and preservation of continence and erection in candidates for radical prostatectomy: an update. Eur Urol 2016;70:301-11.

[101] Moran PS, O'Neill M, Teljeur C, et al. Robot-assisted radical prostatectomy compared with open and laparoscopic approaches: a systematic review and meta-analysis. Int J Urol 2013;20:312-21.

[102] Ficarra V, Novara G, Ahlering TE, et al. Systematic review and metaanalysis of studies reporting potency rates after robot-assisted radical prostatectomy. Eur Urol 2012;62:418-30.

[103] Capogrosso P, Pozzi EP, Celentano V, Sanchez-Salas R, Salonia A. Erectile recovery after radical pelvic surgery: methodological challenges and recommendations for data reporting. J Sex Med 2020;17:7-16.

[104] Isgoren AE, Saitz TR, Serefoglu EC. Erectile function outcomes after robot-assisted radical prostatectomy: is it superior to open retropubic or laparoscopic approach? Sex Med Rev 2014;2:10-23.

[105] Yaxley JW, Coughlin GD, Chambers SK, et al. Robot-assisted laparoscopic prostatectomy versus open radical retropubic prostatectomy: early outcomes from a randomised controlled phase 3 study. Lancet Lond Engl 2016;388:1057-66.

[106] Hunt AA, Choudhury KR, Nukala V, et al. Risk of erectile dysfunction after modern radiotherapy for intact prostate cancer. Prostate Cancer Prostatic Dis 2021;24:128-34.

[107] Nolsøe AB, Jensen CFS, Østergren PB, Fode M. Neglected side effects to curative prostate cancer treatments. Int J Impot Res 2021;33:428-38.

[108] Valerio M, Cerantola Y, Eggener SE, et al. New and established technology in focal ablation of the prostate: a systematic review. Eur Urol 2017;71:17-34
[109] Maggi M, Gentilucci A, Salciccia S, et al. Psychological impact of different primary treatments for prostate cancer: a critical analysis. Andrologia 2019;51:e13157.

[110] Hatzichristou D, Kirana P-S, Banner L, et al. Diagnosing sexual dysfunction in men and women: sexual history taking and the role of symptom scales and questionnaires. J Sex Med 2016;13:1166-82.

[111] Althof SE, Rosen RC, Perelman MA, Rubio-Aurioles E. Standard operating procedures for taking a sexual history. J Sex Med 2013;10:26-35.

[112] Rosen RC, Cappelleri JC, Gendrano N. The International Index of Erectile Function (IIEF): a state-of-the-science review. Int J Impot Res 2002;14:226-44.

[113] Mulhall JP, Goldstein I, Bushmakin AG, Cappelleri JC, Hvidsten K. Validation of the erection hardness score. J Sex Med 2007;4:1626-34.

[114] Richter P, Werner J, Heerlein A, Kraus A, Sauer H. On the validity of the Beck Depression Inventory. A review. Psychopathology 1998;31:160-8.

[115] Zhao B, Hong Z, Wei Y, Yu D, Xu J, Zhang W. Erectile dysfunction predicts cardiovascular events as an independent risk factor: a systematic review and meta-analysis. J Sex Med 2019;16:1005-17.

[116] Poorthuis MHF, Algra AM, Algra AM, Kappelle LJ, Klijn CJM. Femaleand male-specific risk factors for stroke: a systematic review and meta-analysis. JAMA Neurol 2017;74:75-81.

[117] Chokesuwattanaskul R, Thongprayoon C, Pachariyanon P, et al. Erectile dysfunction and atrial fibrillation: a systematic review and meta-analysis. Int J Urol 2018;25:752-7.

[118] Nehra A, Jackson G, Miner M, et al. The Princeton III Consensus recommendations for the management of erectile dysfunction and cardiovascular disease. Mayo Clin Proc 2012;87:766-78.

[119] Ghanem HM, Salonia A, Martin-Morales A. SOP: physical examination and laboratory testing for men with erectile dysfunction. J Sex Med 2013;10:108-10.

[120] Maggi M, Buvat J, Corona G, Guay A, Torres LO. Hormonal causes of male sexual dysfunctions and their management (hyperprolactinemia, thyroid disorders, GH disorders, and DHEA). J Sex Med 2013;10:661-77.

[121] Zou Z, Lin H, Zhang Y, Wang R. The role of nocturnal penile tumescence and rigidity (NPTR) monitoring in the diagnosis of psychogenic erectile dysfunction: a review. Sex Med Rev 2019;7:442-54.

[122] Hatzichristou DG, Hatzimouratidis K, Ioannides E, Yannakoyorgos K, Dimitriadis G, Kalinderis A. Nocturnal penile tumescence and rigidity monitoring in young potent volunteers: reproducibility, evaluation criteria and the effect of sexual intercourse. J Urol 1998;159:1921-6.

[123] Edgar R, Trip EJ, Wolterink GJW, Veltink PH, Beck JJH. New methods for the monitoring of nocturnal erections. Int J Impot Res. In press. https://doi.org/10.1038/s41443-020-00365-9.

[124] Qin F, Gao L, Qian S, Fu F, Yang Y, Yuan J. Advantages and limitations of sleep-related erection and rigidity monitoring: a review. Int J Impot Res 2018;30:192-201.

[125] Nascimento B, Miranda EP, Terrier J-E, Carneiro F, Mulhall JP. A critical analysis of methodology pitfalls in duplex Doppler ultrasound in the evaluation of patients with erectile dysfunction: technical and interpretation deficiencies. J Sex Med 2020;17: 1416-22.

[126] Capogrosso P, Frey A, Jensen CFS, et al. Low-intensity shock wave therapy in sexual medicine-clinical recommendations from the European Society of Sexual Medicine (ESSM). J Sex Med 2019;16:1490-505.

[127] Trost LW, Munarriz R, Wang R, Morey A, Levine L. External mechanical devices and vascular surgery for erectile dysfunction. J Sex Med 2016;13:1579-617. 
[128] Nguyen HMT, Gabrielson AT, Hellstrom WJG. Erectile dysfunction in young men-a review of the prevalence and risk factors. Sex Med Rev 2017;5:508-20.

[129] Hatzimouratidis K, Salonia A, Adaikan G, et al. Pharmacotherapy for erectile dysfunction: recommendations from the Fourth International Consultation for Sexual Medicine (ICSM 2015). J Sex Med 2016;13:465-88.

[130] Frühauf S, Gerger H, Schmidt HM, Munder T, Barth J. Efficacy of psychological interventions for sexual dysfunction: a systematic review and meta-analysis. Arch Sex Behav 2013;42:915-33.

[131] Kloner RA, Goldstein I, Kirby MG, Parker JD, Sadovsky R. Cardiovascular safety of phosphodiesterase type 5 inhibitors after nearly 2 decades on the market. Sex Med Rev 2018;6:583-94.

[132] Adamou C, Ntasiotis P, Athanasopoulos A, Kallidonis P. The hemodynamic interactions of combination therapy with $\alpha$-blockers and phosphodiesterase-5 inhibitors compared to monotherapy with $\alpha$-blockers: a systematic review and meta-analysis. Int Urol Nephrol 2020;52:1407-20.

[133] Sakuma I, Akaishi Y, Tomioka H, Sato A, Kitabatake A, Hattori Y. Interactions of sildenafil with various coronary vasodilators in isolated porcine coronary artery. Eur J Pharmacol 2002;437: 155-63.

[134] Ishizuka N, Saito K, Akima M, Matsubara S, Saito M. Hypotensive interaction of sildenafil and nicorandil in rats through the cGMP pathway but not by K(ATP) channel activation. Jpn J Pharmacol 2000;84:316-24.

[135] Anaissie J, Hellstrom WJ. Clinical use of alprostadil topical cream in patients with erectile dysfunction: a review. Res Rep Urol 2016;8:123-31.

[136] Cai T, Palumbo F, Liguori G, et al. The intra-meatal application of alprostadil cream (Vitaros $®$ ) improves drug efficacy and patient's satisfaction: results from a randomized, two-administration route, cross-over clinical trial. Int J Impot Res 2019;31:119-25.

[137] Coombs PG, Heck M, Guhring P, Narus J, Mulhall JP. A review of outcomes of an intracavernosal injection therapy programme. BJU Int 2012;110:1787-91.

[138] Duncan C, Omran GJ, Teh J, Davis NF, Bolton DM, Lawrentschuk N. Erectile dysfunction: a global review of intracavernosal injectables. World J Urol 2019;37:1007-14.

[139] Porst H, Burnett A, Brock G, et al. SOP conservative (medical and mechanical) treatment of erectile dysfunction. J Sex Med 2013;10:130-71.

[140] Eardley I, Donatucci C, Corbin J, et al. Pharmacotherapy for erectile dysfunction. J Sex Med 2010;7:524-40.

[141] Porst H. Current perspectives on intracavernosal pharmacotherapy for erectile dysfunction. Int J Impot Res 2000;12(Suppl 4):S91-100.

[142] Vardi Y, Appel B, Jacob G, Massarwi O, Gruenwald I. Can lowintensity extracorporeal shockwave therapy improve erectile function? A 6-month follow-up pilot study in patients with organic erectile dysfunction. Eur Urol 2010;58:243-8.

[143] Sokolakis I, Hatzichristodoulou G. Clinical studies on low intensity extracorporeal shockwave therapy for erectile dysfunction: a systematic review and meta-analysis of randomised controlled trials. Int J Impot Res 2019;31:177-94.

[144] Bechara A, Casabé A, De Bonis W, Ciciclia PG. Twelve-month efficacy and safety of low-intensity shockwave therapy for erectile dysfunction in patients who do not respond to phosphodiesterase type 5 inhibitors. Sex Med 2016;4:e225-32.

[145] Vinay J, Moreno D, Rajmil O, Ruiz-Castañe E, Sanchez-Curbelo J. Penile low intensity shock wave treatment for PDE5I refractory erectile dysfunction: a randomized double-blind sham-controlled clinical trial. World J Urol. In press. https://doi.org/10.1007/ s00345-020-03373-y.
[146] Campbell JD, Trock BJ, Oppenheim AR, Anusionwu I, Gor RA, Burnett AL. Meta-analysis of randomized controlled trials that assess the efficacy of low-intensity shockwave therapy for the treatment of erectile dysfunction. Ther Adv Urol 2019;11:1756287219838364.

[147] Yuan J, Hoang AN, Romero CA, Lin H, Dai Y, Wang R. Vacuum therapy in erectile dysfunction-science and clinical evidence. Int $\mathrm{J}$ Impot Res 2010;22:211-9.

[148] Cavallini G. Resolution of erectile dysfunction after an andrological visit in a selected population of patients affected by psychogenic erectile dysfunction. Asian J Androl 2017;19:219-22.

[149] Brotto L, Atallah S, Johnson-Agbakwu C, et al. Psychological and interpersonal dimensions of sexual function and dysfunction. J Sex Med 2016;13:538-71.

[150] Bajic P, Mahon J, Faraday M, Sadeghi-Nejad H, Hakim L, McVary KT. Etiology of erectile dysfunction and duration of symptoms in patients undergoing penile prosthesis: a systematic review. Sex Med Rev 2020;8:333-7.

[151] Muneer A, Fowler S, Ralph DJ, Summerton DJ, Rees RW, BAUS Section of Andrology, Genitourethral Surgery. UK practice for penile prosthesis surgery: baseline analysis of the British Association of Urological Surgeons (BAUS) penile prosthesis audit. BJU Int 2021;127:326-31.

[152] Palmisano F, Boeri L, Cristini C, et al. Comparison of infrapubic vs penoscrotal approaches for 3-piece inflatable penile prosthesis placement: do we have a winner? Sex Med Rev 2018;6:631-9.

[153] Otero JR, Cruz CR, Gómez BG, et al. Comparison of the patient and partner satisfaction with $700 \mathrm{CX}$ and Titan penile prostheses. Asian J Androl 2017; 19:321-5.

[154] Chierigo F, Capogrosso P, Dehò F, et al. Long-term follow-up after penile prosthesis implantation-survival and quality of life outcomes. J Sex Med 2019;16:1827-33.

[155] Pisano F, Falcone M, Abbona A, et al. The importance of psychosexual counselling in the re-establishment of organic and erotic functions after penile prosthesis implantation. Int J Impot Res 2015;27:197-200.

[156] Atri E, Wong V, Barengo NC, Nieder AM, Polackwich AS. A comparison between AMS 700 and Coloplast Titan: a systematic literature review. Cureus 2020;12:e11350.

[157] Serefoglu EC, McMahon CG, Waldinger MD, et al. An evidencebased unified definition of lifelong and acquired premature ejaculation: report of the second International Society for Sexual Medicine Ad Hoc Committee for the definition of premature ejaculation. J Sex Med 2014;11:1423-41.

[158] Waldinger MD, Schweitzer DH. Changing paradigms from a historical DSM-III and DSM-IV view toward an evidence-based definition of premature ejaculation. Part II-proposals for DSM-V and ICD-11. J Sex Med 2006;3:693-705.

[159] Porst H, Montorsi F, Rosen RC, Gaynor L, Grupe S, Alexander J. The Premature Ejaculation Prevalence and Attitudes (PEPA) survey: prevalence, comorbidities, and professional help-seeking. Eur Urol 2007;51:816-23, discussion 824.

[160] Serefoglu EC, Yaman O, Cayan S, et al. Prevalence of the complaint of ejaculating prematurely and the four premature ejaculation syndromes: results from the Turkish Society of Andrology Sexual Health Survey. J Sex Med 2011;8:540-8.

[161] Gao J, Zhang X, Su P, et al. Prevalence and factors associated with the complaint of premature ejaculation and the four premature ejaculation syndromes: a large observational study in China. J Sex Med 2013;10:1874-81.

[162] Althof SE, McMahon CG, Waldinger MD, et al. An update of the International Society of Sexual Medicine's guidelines for the diagnosis and treatment of premature ejaculation (PE). J Sex Med 2014;11:1392-422. 
[163] Rowland DL, Slob AK. Premature ejaculation: psychophysiological considerations in theory, research, and treatment. Annu Rev Sex Res 1997;8:224-53.

[164] Giuliano F, Patrick DL, Porst H, et al. Premature ejaculation: results from a five-country European observational study. Eur Urol 2008;53:1048-57.

[165] Kempeneers P, Andrianne R, Bauwens S, Georis I, Pairoux J-F, Blairy S. Functional and psychological characteristics of Belgian men with premature ejaculation and their partners. Arch Sex Behav 2013;42:51-66.

[166] Rosen RC, McMahon CG, Niederberger C, Broderick GA, Jamieson C, Gagnon DD. Correlates to the clinical diagnosis of premature ejaculation: results from a large observational study of men and their partners. J Urol 2007;177:1059-64, discussion 1064.

[167] Waldinger MD, Zwinderman AH, Olivier B, Schweitzer DH. Geometric mean IELT and premature ejaculation: appropriate statistics to avoid overestimation of treatment efficacy. J Sex Med 2008;5:492-9.

[168] Symonds T, Perelman MA, Althof S, et al. Development and validation of a premature ejaculation diagnostic tool. Eur Urol 2007;52:565-73.

[169] Arafa M, Shamloul R. Development and evaluation of the Arabic Index of Premature Ejaculation (AIPE). J Sex Med 2007;4:1750-6.

[170] Lue TF, Giuliano F, Montorsi F, et al. Summary of the recommendations on sexual dysfunctions in men. J Sex Med 2004;1:6-23.

[171] Porst H, McMahon CG, Althof SE, et al. Baseline characteristics and treatment outcomes for men with acquired or lifelong premature ejaculation with mild or no erectile dysfunction: integrated analyses of two phase 3 dapoxetine trials. J Sex Med 2010;7:2231-42.

[172] Castiglione F, Albersen M, Hedlund P, Gratzke C, Salonia A, Giuliano F. Current pharmacological management of premature ejaculation: a systematic review and meta-analysis. Eur Urol 2016;69: 904-16.

[173] Pryor JL, Althof SE, Steidle C, et al. Efficacy and tolerability of dapoxetine in treatment of premature ejaculation: an integrated analysis of two double-blind, randomised controlled trials. Lancet Lond Engl 2006;368:929-37.

[174] McMahon C, Lee SW, Kim SW, Moon DG, Kongkanand A, Tantiwongse K. The Asia-Pacific flexible dose study of dapoxetine and patient satisfaction in premature ejaculation therapy: the PASSION study. Sex Med 2016;4:e18-27.

[175] Yue F-G, Dong L, Hu T-T, Qu X-Y. Efficacy of dapoxetine for the treatment of premature ejaculation: a meta-analysis of randomized clinical trials on intravaginal ejaculatory latency time, patient-reported outcomes, and adverse events. Urology 2015;85: 856-61.

[176] Qin Z, Wang Y, Zhu J, et al. Safety and efficacy characteristics of oral drugs in patients with premature ejaculation: a Bayesian network meta-analysis of randomized controlled trials. Int J Impot Res 2019;31:356-68.

[177] EMA. FORTACINTM: Summary of product characteristics. 2014.

[178] Henry R, Morales A, Wyllie MG. TEMPE: topical eutectic-like mixture for premature ejaculation. Expert Opin Drug Deliv 2008;5:251-61.

[179] Dinsmore WW, Hackett G, Goldmeier D, et al. Topical eutectic mixture for premature ejaculation (TEMPE): a novel aerosol-delivery form of lidocaine-prilocaine for treating premature ejaculation. BJU Int 2007;99:369-75.

[180] Waldinger MD. Drug treatment options for premature ejaculation. Expert Opin Pharmacother 2018;19:1077-85.

[181] Morales A. Evolving therapeutic strategies for premature ejaculation: the search for on-demand treatment-topical versus systemic. Can Urol Assoc J 2012;6:380-5.
[182] Jian Z, Wei X, Ye D, Li H, Wang K. Pharmacotherapy of premature ejaculation: a systematic review and network meta-analysis. Int Urol Nephrol 2018;50:1939-48.

[183] Waldinger MD, Hengeveld MW, Zwinderman AH, Olivier B. Effect of SSRI antidepressants on ejaculation: a double-blind, randomized, placebo-controlled study with fluoxetine, fluvoxamine, paroxetine, and sertraline. J Clin Psychopharmacol 1998;18: 274-81.

[184] Zhang D, Cheng Y, Wu K, Ma Q Jiang J, Yan Z. Paroxetine in the treatment of premature ejaculation: a systematic review and meta-analysis. BMC Urol 2019;19:2.

[185] Wu P-C, Hung C-S, Kang Y-N, Wu P-C. Tolerability and optimal therapeutic dosage of clomipramine for premature ejaculation: a systematic review and meta-analysis. Sex Med 2021;9:100283.

[186] Yi Z-M, Chen S-D, Tang Q-Y, Tang Q-Y, Zhai S-D. Efficacy and safety of sertraline for the treatment of premature ejaculation: systematic review and meta-analysis. Medicine (Baltimore) 2019;98: e15989.

[187] Martyn-St James M, Cooper K, Kaltenthaler E, et al. Tramadol for premature ejaculation: a systematic review and meta-analysis. BMC Urol 2015;15:6.

[188] Sharma AP, Sharma G, Tyagi S, et al. Safety and efficacy of "ondemand" tramadol in patients with premature ejaculation: an updated meta-analysis. Int Braz J Urol 2021;47.

[189] Bar-Or D, Salottolo KM, Orlando A, Winkler JV, Tramadol ODT Study Group. A randomized double-blind, placebo-controlled multicenter study to evaluate the efficacy and safety of two doses of the tramadol orally disintegrating tablet for the treatment of premature ejaculation within less than 2 minutes. Eur Urol 2012;61:736-43.

[190] Kirby EW, Carson CC, Coward RM. Tramadol for the management of premature ejaculation: a timely systematic review. Int J Impot Res 2015;27:121-7.

[191] Hamidi-Madani A, Motiee R, Mokhtari G, Nasseh H, Esmaeili S, Kazemnezhad E. The efficacy and safety of on-demand tramadol and paroxetine use in treatment of life long premature ejaculation: a randomized double-blind placebo-controlled clinical trial. J Reprod Infertil 2018;19:10-5.

[192] Sridharan K, Sivaramakrishnan G, Sequeira RP, Al-Khaja KA. Pharmacological interventions for premature ejaculation: a mixedtreatment comparison network meta-analysis of randomized clinical trials. Int J Impot Res 2018;30:215-23.

[193] Martyn-St James M, Cooper K, Ren S, et al. Phosphodiesterase type 5 inhibitors for premature ejaculation: a systematic review and meta-analysis. Eur Urol Focus 2017;3:119-29.

[194] Liu H, Zhang M, Huang M, et al. Comparative efficacy and safety of drug treatment for premature ejaculation: a systemic review and Bayesian network meta-analysis. Andrologia 2020;52:e13806.

[195] Althof SE. Psychosexual therapy for premature ejaculation. Transl Androl Urol 2016;5:475-81.

[196] Ventus D, Gunst A, Arver S, et al. Vibrator-assisted start-stop exercises improve premature ejaculation symptoms: a randomized controlled trial. Arch Sex Behav 2020;49:1559-73.

[197] Stephenson KR, Welch JP. Statistical mediators of the association between mindfulness and sexual experiences in men with impaired sexual function. Arch Sex Behav 2020;49:1545-57.

[198] Cormio L, Massenio P, La Rocca R, Verze P, Mirone V, Carrieri G. The combination of dapoxetine and behavioral treatment provides better results than dapoxetine alone in the management of patients with lifelong premature ejaculation. J Sex Med 2015;12:1609-15.

[199] Mulhall JP, Albertsen PC. Hemospermia: diagnosis and management. Urology 1995;46:463-7. 
[200] Ng YH, Seeley JP, Smith G. Haematospermia as a presenting symptom: outcomes of investigation in 300 men. Surgeon 2013;11:35-8.

[201] Kumar P, Kapoor S, Nargund V. Haematospermia-a systematic review. Ann R Coll Surg Engl 2006;88:339-42.

[202] Efesoy O, Çayan S, Aşcı R, Orhan İ, Yaman Ö. Hematospermia is rarely related to genitourinary cancer: lessons learned from 15 years of experience with 342 cases. Int J Impot Res. In press. https://doi.org/10.1038/s41443-020-0330-9.

[203] Bamberger E, Madeb R, Steinberg J, et al. Detection of sexually transmitted pathogens in patients with hematospermia. Isr Med Assoc J IMAJ 2005;7:224-7.

[204] Bhaduri S, Riley VC. Haematospermia associated with malignant hypertension. Sex Transm Infect 1999;75:200.

[205] Amasanti M, Huang C, Lovell B. Hematospermia as a manifestation of severe hypertension in a young man. Clin Case Rep 2017;5:446-8.

[206] Munkel Witz R, Krasnokutsky S, Lie J, Shah SM, Bayshtok J, Khan SA. Current perspectives on hematospermia: a review. J Androl 1997;18:6-14.
[207] Manohar T, Ganpule A, Desai M. Transrectal ultrasound- and fluoroscopic-assisted transurethral incision of ejaculatory ducts: a problem-solving approach to nonmalignant hematospermia due to ejaculatory duct obstruction. J Endourol 2008;22:1531-5.

[208] Suh Y, Gandhi J, Joshi G, et al. Etiologic classification, evaluation, and management of hematospermia. Transl Androl Urol 2017;6:959-72.

[209] Ahmad I, Krishna NS. Hemospermia. J Urol 2007;177:1613-8.

[210] Han M, Brannigan RE, Antenor JAV, Roehl KA, Catalona WJ. Association of hemospermia with prostate cancer. J Urol 2004;172: 2189-92.

[211] Mittal PK, Camacho JC, Sahani DV, et al. Hematospermia evaluation at MR imaging. Radiographics 2016;36:1373-89.

[212] Expert Panel on Urologic Imaging, Hosseinzadeh K, Oto A, et al. ACR appropriateness Criteria $\mathbb{R}$ hematospermia. J Am Coll Radiol 2017;14:S154-9.

[213] Li B-J, Zhang C, Li K, et al. Clinical analysis of the characterization of magnetic resonance imaging in 102 cases of refractory haematospermia. Andrology 2013;1:948-56. 